\title{
Quasi-oppositional Grey Wolf Optimizer Algorithm for Economic Dispatch
}

\author{
Diptanu Das*, Aniruddha Bhattacharya and Rup Narayan Ray \\ Department of Electrical Engineering, National Institute of Technology Agartala, Purba Barjala, \\ Jirania - 799046, Tripura, India; \\ diptanuonline@yahoo.co.in, bhatta.aniruddha@gmail.com,rupnarayan_r@yahoo.co.in
}

\begin{abstract}
Objectives: To minimize the fuel price of generator while satisfying different constraints. Valve point effects and multiple fuel option are also considered in some cases. Methods: Quasi-Oppositional Grey Wolf Optimizer algorithm is applied here for solving different economic dispatch problems. Grey Wolf Optimizer is a meta-heuristic method, motivated by social behaviour of grey wolves. Quasi-Oppositional learning is implemented in the present work within Grey Wolf Optimizer for improving the quality of solution in minimum time. Quasi-opposite numbers are used within the algorithm in place of normal random numbers for improving the convergence speed. Findings: The proposed technique is applied to six different systems to test the efficiency of the algorithm. Simulation results obtained by this method are compared with those obtained by some well-known optimization methods to show the robustness and superiority of this technique. Simulation results also show that the computational efficiency of Quasi-Oppositional Grey Wolf optimizer is better as compared to several previously developed optimization methods. Improvement: It is found that the convergence speed, success rate, efficiency and solution quality of the proposed algorithm is improved.
\end{abstract}

Keywords: Economic Load Dispatch, Oppositional Based Learning, Quasi-oppositional Grey Wolf Optimizer, Valve Point Effects

\section{Introduction}

Minimization of power generation cost of fossil fuel based plants is a big challenge for the power engineers. Therefore, in recent decades, researchers have given much attention for minimizing the cost of power production. The objective of Economic Load Dispatch (ELD) is to minimize the cost of power generation while satisfying various equality and inequality constraints. Many techniques have been developed to solve the economic dispatch problems. Erstwhile, many classical optimization methods like Linear programming, Dynamic Programming 2 , Lagrangian method $\underline{3}$ etc. have been devel- oped to solve ELD problems but they suffer from various limitations when deals with non-smooth cost functions.

A practical ELD problem considers the effect of prohibited zone, ramp rate limit and valve point. So the problem becomes a complex optimization problem which is very difficult to solve by traditional methods. In recent years, various artificial intelligence methods like Genetic Algorithm (GA) ${ }^{4}$, Simulated annealing 5 , Cuckoo search algorithm ${ }^{6}$, Particle Swarm Optimization (PSO) ${ }^{\underline{7}}$, Modified Artificial Bee Colony Optimization (MABCA) $\stackrel{8}{\text {, }}$ Differential Evolution (DE) ${ }^{9}$, Fuzzy Adaptive Chaotic Ant Swarm Optimization (CASO) $)^{10}$, Real Coded Chemical

${ }^{*}$ Author for correspondence 
Reaction Optimization (RCCRO) $)^{11}$, Oppositional Real Coded Chemical Reaction Optimization (ORCCRO) $\frac{12}{}$, Biogeography-based Optimization (BBO) $\frac{13}{3}$, Teaching Learning based Optimization (TLBO) $\frac{14}{4}$, Exchange Market Algorithm (EMA) $\frac{15}{}$, One Rank Cuckoo Search Algorithm (ORCSA) $\frac{16}{}$, Real Coded Genetic Algorithm (RCGA) ${ }^{17}$, Krill Herd Algorithm (KHA) $\frac{18}{\text {, Grey Wolf }}$ Optimizer (GWO) $\stackrel{19}{ }$, Ant Lion Optimization (ALO) ${ }^{20}$, Kinetic Gas Molecule Optimization (KGMO)르 have been proposed by the researchers for solving non-convex ELD problems due to their ability of searching global optimum solution for non-smooth cost function.

The techniques mentioned above may be fruitful for solving non-convex economic load dispatch problems. In any case, these algorithms do not ensure that the solution is the global best solutions. Therefore, various hybridisations and modifications of DE, PSO, GA, EP, BBO have been made. Some important hybrid methods like Improved fast evolutionary programming ${ }^{22}$, DE with generator of chaos sequences and sequential quadratic programming ${ }^{23}$, Directional Search GA (DSGA) ${ }^{24}$, New PSO with local random search (NPSO_LRS) ${ }^{25}$, Variable scaling hybrid differential evolution $\frac{26}{}$, Bacterial foraging with Nelder-Mead algorithm ${ }^{27}$, Self-organising hierarchical $\mathrm{PSO}^{28}$, Improved coordinated aggregation-based $\mathrm{PSO}^{29}$, Improved $\mathrm{PSO}^{30}$, Hybrid differential evolution with $\mathrm{BBO}(\mathrm{DE} / \mathrm{BBO})^{\frac{31}{2}}$, Oppositional Invasive Weed Optimization (OIWO $)^{\frac{32}{2}}$, Hybrid chemical reaction optimization with DE (HCRO-DE) $\frac{33}{3}$, Modified Differential Evaluation (MDE) $)^{34}$, Hybrid ACO-ABC-HS $\frac{35}{5}$ etc, have been developed for solving various types of economic load dispatch problems.

In 2014, have developed a new meta-heuristic optimization method called Grey Wolf Optimizer (GWO) ${ }^{36}$. This method is inspired by the hunting behaviour of grey wolves. This optimization technique has been tested on 29 well-known benchmark functions ${ }^{36}$ and it was found that GWO algorithm gives better result as compared to other well-known optimization techniques.

Oppositional Based Learning (OBL) $)^{37}$ has been proposed by Tizhoosh in order to improve back propagation in neural networks. In order to approach the solution,
OBL exploits the opposite numbers. By contrasting a number compared to the opposite number, a compact search space is required to obtain the correct solution. It has been demonstrated that a quasi-opposite number ${ }^{38}$ is likely to be nearer to the solution as compared to an arbitrary number. It has additionally been demonstrated that a quasi-opposite number is typically nearer to the solution compared to an opposite number. As quasi-opposition based learning is proved to have improved computational efficiency, the present authors have adopted this methodology in GWO (QOGWO) for accelerating the speed of convergence of GWO to a greater extent. In this paper, the Quasi Oppositional Grey Wolf Optimizer (QOGWO) algorithm is used for solving various ELD problems and results obtained by QOGWO method are compared to other optimization techniques. The details of this proposed technique have been discussed in section 3 .

Section 2 gives the problem formulation and brief description of various economic load dispatch problems. Section 3 describes a short description of GWO algorithm. Short description about QOGWO algorithm is explained in Section 4. Simulation results are discussed in Section 5. The conclusion is described in Section 6.

\section{Problem Formulation}

\subsection{Objective Function}

\subsubsection{Quadratic Cost Function of ELD}

The objective function ${ }^{12}$ of economic dispatch problem for this case can be written as

$$
C_{T}=\min \sum_{i=1}^{N} C_{i}\left(\mathrm{~W}_{i}\right)=\min \sum_{i=1}^{N} a_{1 i}+b_{1 i} W_{i}+c_{1 i} W_{i}^{2}
$$

where, $C_{i}\left(W_{i}\right)$ is the cost function of $i^{\text {th }}$ generator; $a_{12}$ $b_{1 i} c_{1 i}$ are the coefficients of fuel cost of $i^{\text {th }}$ unit; $N$ represents number of units; $W_{i}$ is the power output of $i^{\text {th }}$ unit. 


\subsubsection{Economic Dispatch with Valve Point Loading Effect}

The overall objective function $C_{T}$ of ELD with valve point ${ }^{12}$ can be expressed as follows

$$
C_{T}=\left(\sum_{i=1}^{N} C_{i}\left(W_{i}\right)\right)=\left(\sum_{i=1}^{N} a_{1 i}+b_{1 i} W_{i}+c_{1 i} W_{i}^{2}+\left|E_{1 i} \times \sin \left\{F_{1 i} \times\left(W_{i}^{\text {min }}-W_{i}\right)\right\}\right|\right)
$$

where, $E_{1 i}$ and $F_{1 i}$ represents the coefficients of unit $i$ reflecting the effect of valve point.

\subsubsection{Fuel Price Function Considering the Effect of Valve -point and Multiple Fuel}

In a network, if $N$ represents number of generator and $n_{F}$ is the fuel option of individual unit, then the generator fuel price function considering the effect of valve point and multiple fuel can be represented by

$$
C_{i p}\left(W_{i}\right)=\sum_{i=1}^{N}\left(a_{1 i p}+b_{1 i p} W_{i}+c_{1 i p} W_{i}^{2}+\left|E_{1 i p} \times \sin \left\{\mathrm{F}_{\text {lip }} \times\left(W_{i p}^{\mathrm{min}}-W_{i}\right)\right\}\right|\right)
$$

if

$$
W_{i p}^{\min } \leq W_{i} \leq W_{i p}^{\max } \quad p=1,2, \ldots \ldots \ldots, n_{F}
$$

where, $W_{i p}^{\min }$ and $W_{i p}^{\max }$ are the lower and upper limit of thermal power generation with fuel option $p ; a_{1 i p}$ $b_{1 i p} c_{1 i p}, E_{1 i p}, F_{1 i p}$ represent the coefficients of fuel price of $i^{\text {th }}$ generator with fuel option $p$.

\subsection{Constraints of ELD problem}

\subsubsection{Real Power Constraint or Demand Constraint}

The total generation must be equal to transmission loss and system demands. This can be represented as

$$
\sum_{i=1}^{N} W_{i}-\left(W_{D}+W_{L}\right)=0
$$

where, $W_{L}, W_{D}$ represents the total transmission loss and total system demand respectively. The transmission loss $W_{L}$ can be calculated as

$$
W_{L}=\sum_{i=1}^{N} \sum_{j=1}^{N} W_{i} B_{i j} W_{j}+\sum_{i=1}^{N} B_{0 i} W_{i}+B_{00}
$$

\subsubsection{Generator Operating Limits Constraint}

The power generated by individual generator must vary within it's maximum and minimum limit. Therefore, mathematically this may be written as

$$
W_{i}^{\min } \leq W_{i} \leq W_{i}^{\max } \quad i=1,2,3 \ldots \ldots \ldots . . . N
$$

where, $\quad{ }^{\min }$ and $W_{i}^{\max }$ are the minimum and maximum real power output of the $i^{\text {th }}$ generator.

\subsubsection{Ramp Rate Limit Constraints}

In practical circumstances, the working range of each online unit may be confined by the ramp rate limit ${ }^{12}$. Depending on up $\left(U R_{i}\right)$ and down $\left(D R_{i}\right)$ ramp rate limits, the generation can be increased or decreased.

If generation increases

$$
W_{i}-W_{i 0} \leq U R_{i}
$$

If generation decreases

$$
W_{i 0}-W_{i} \leq D R_{i}
$$

where, $W_{i 0}$ represents power generation of $i^{\text {th }}$ unit at earlier hour. 


\subsubsection{Prohibited Zone Constraint}

Each generator might have some zone of operation where operation is limited because of fault in the machines, steam valve operation, boilers, vibration in shafts etc ${ }^{12}$. Thus, a discontinuous cost curve is produced corresponding to prohibited operating zone. Prohibited operating zone may be formulated as

$$
\begin{aligned}
& W_{i}^{\min } \leq W_{i} \leq W_{i, 1}^{l} \\
& \text { or } \\
& W_{i, k-1}^{u} \leq W_{i} \leq W_{i, k}^{l} \quad k=2,3, \ldots \ldots \ldots n_{i} \\
& \text { or } \\
& W_{i, n_{i}}^{u} \leq W_{i} \leq W_{i}^{\max }
\end{aligned}
$$

where, $k$ represents total prohibited zone numbers of $i^{\text {th }}$ unit. $W_{i, k}^{u}$ and $W_{i, k}^{l}$ represents higher and lower limit of the $k^{\text {th }}$ prohibited zone; $n_{i}$ represents total prohibited zones number of $i^{\text {th }}$ unit. During optimization, if $W_{i, k}^{u} \geq W_{i} \geq\left(\mathrm{W}_{i, k}^{u}+W_{i, k}^{l}\right) / 2$ then $W_{i}$ will be fixed to $W_{i, k}^{u}$. Mathematically this can be expressed as

$$
\begin{aligned}
& W_{i}=W_{i, k}^{u} \\
& \text { if } W_{i, k}^{u} \geq W_{i} \geq\left(\mathrm{W}_{i, k}^{u}+W_{i, k}^{l}\right) / 2 \quad k=2,3, \ldots \ldots . . n_{i}
\end{aligned}
$$

If $W_{i, k}^{l}<W_{i}<\left(\mathrm{W}_{i, k}^{u}+W_{i, k}^{l}\right) / 2$ then $W_{i}$ will be fixed to $W_{i, k}^{l}$. Mathematically this can be expressed as

$$
\begin{aligned}
& \quad W_{i}=W_{i, k}^{l} \\
& \text { if } W_{i, k}^{l}<W_{i}<\left(\mathrm{W}_{i, k}^{u}+W_{i, k}^{l}\right) / 2 k=2,3, \ldots \ldots . . n_{i}
\end{aligned}
$$

\subsection{Calculation of Slack Generator Power Output}

\subsubsection{Without Transmission Loss}

$$
W_{N}=W_{D}-\sum_{i=1}^{(N-1)} W_{i}
$$

\subsubsection{With Transmission Loss}

$$
W_{N}=W_{D}+W_{L}-\sum_{i=1}^{N-1} W_{i}
$$

Using equation (6) and (14) the modified equation may be written as

$$
B_{N N} W_{N}^{2}+W_{N}\left(2 \sum_{i=1}^{N-1} B_{N i} W_{i}+B_{0 N}-1\right)+\left(W_{D}+\sum_{i=1}^{N-1} \sum_{j=1}^{N-1} W_{i} B_{i j} W_{j}+\sum_{i=1}^{N-1} B_{0 i} W_{i}-\sum_{i=1}^{N-1} W_{i}+B_{00}\right)=0
$$

$$
W_{N} \text { is the same as mentioned } \text { in }^{31}
$$

\section{Grey Wolf Optimizer}

This section of the paper presents a newly developed optimization method called grey wolf optimizer, which has been proposed in ${ }^{36}$.

Grey wolves usually live in a group of 5-12 members. Alpha is the group leader and their main their main tasks are decisions making, hunting etc. The second member in the hierarchy is Beta and it helps Alpha in order to make the decision. Delta and Omega are the lowest ranking grey wolves. Omega wolves are not an important individual, but entire group facing the fighting problem if they lose any omega. Deltas are responsible for watching the boundary of territory, carrying weak grey wolves, and help the Alpha at the time of hunting.

\subsection{Encircling}

Hunting behaviour of the grey wolf is started by encircling 
the prey. For mathematically model of this behaviour following equations have been developed.

$$
\begin{aligned}
& \vec{D}=\left|\overrightarrow{\mathrm{S}} \vec{G}_{P}(t)-\vec{G}(t)\right| \\
& \vec{G}(t+1)=\vec{G}_{P}(t)-\vec{P} \vec{Q}
\end{aligned}
$$

Here, t, $\vec{P}$ and $\vec{S}$ are the current iteration and coefficients vectors respectively. $\vec{G}_{P}$ represents prey's position and $\vec{G}$ is the grey wolf's position. $\vec{P}$ and $\vec{S}$ can be formulated as follows

$$
\begin{aligned}
& \vec{P}=2 \vec{s}_{1} \cdot \vec{y}^{-} \vec{s} \\
& \vec{S}=2 \cdot \overrightarrow{\mathrm{y}}_{2}
\end{aligned}
$$

Here the value of $\vec{s}$ are decreased in the iterative process from 2 to $0 . \vec{y}_{1}$ and $\vec{y}_{2}$ are the random vectors in [0 $1]$.

\subsection{Hunting}

Alpha wolves are always guiding the other grey wolves at the time of hunting. But in an abstract place, it is very difficult to guess the prey's optimal location. According to the best search agent position, other search agents' positions are updated. This behaviour is mathematically modelled using the following equations

$$
\begin{aligned}
& \vec{D}_{\alpha}=\left|\vec{S}_{1} \cdot \vec{G}_{\alpha}-\vec{G}\right| \\
& \vec{D}_{\beta}=\left|\vec{S}_{2} \cdot \vec{G}_{\beta}-\vec{G}\right| \\
& \vec{D}_{\delta}=\left|\vec{S}_{3} \cdot \vec{G}_{\delta}-\vec{G}\right| \\
& \vec{G}_{1}=\vec{G}_{\alpha}-\vec{P}_{1} \cdot\left(\overrightarrow{\mathrm{Q}}_{\alpha}\right)
\end{aligned}
$$

$$
\begin{aligned}
& \vec{G}_{2}=\vec{G}_{\beta}-\vec{P}_{2} \cdot\left(\overrightarrow{\mathrm{Q}}_{\beta}\right) \\
& \vec{G}_{3}=\vec{G}_{\delta}-\vec{P}_{3} \cdot\left(\overrightarrow{\mathrm{Q}}_{\delta}\right) \\
& \vec{G}(t+1)=\frac{\vec{G}_{1}+\vec{G}_{2}+\vec{G}_{3}}{3}
\end{aligned}
$$

\subsection{Exploitation}

The hunting process of grey wolves has been stopped after attacking the prey. In order to mathematically model this, the vector a $(\vec{S})$ should be decreased. $\vec{P}$ represents the random number in the interval $[-2 s, 2 s]$ and its value is reduced from 2 to 0 . If random value $\vec{P}$ is in position $[-1,1]$, then the next search agent may occupy in any location between the current location of prey and the current location of search agent. When $|\vec{P}|<1$, the grey wolves assault the prey.

\subsection{Exploration}

Grey Wolves wander from one place to another in order to search a prey and they unite again to assault the prey. To model this behaviour, $\vec{P}$ is used having random values less than -1 or more than 1 or in order to separate the search agents from the prey.

\subsection{GWO Algorithm}

- Initialize the population matrix according to the number of search agent and dimension of the problem.

- Initialize $\vec{S}, \vec{P}$ and $\vec{S}$

- Calculate the fitness value. The position representing best fitness function is denoted by $\vec{G}_{\alpha}$ and the positions of second and third best fitness function are denoted by $\vec{G}_{\beta}$ and $\vec{G}_{\delta}$ respectively.

- Update search agents' position using (20-25). 
- Update $\vec{S}, \vec{P}$ and $\vec{S}$

- Calculate the fitness value of all modified sets.

- Update the values of $\vec{G}_{\alpha}, \vec{G}_{\beta}$ and $\vec{G}_{\delta}$

- Repeat the steps (iv)-(vii) until the termination criteria are fulfilled otherwise stop the process.

\section{Oppositional based Learning}

Tizhoosh has proposed Oppositional based learning technique to enhance computational speed and quicken the rate of convergence of various optimization algorithms. For randomly generated population number, it is not possible to guess about the value optimal solution and that is why time required to reach optimal solution is large. In OBL, opposite numbers are introduced along with population numbers. It is found that OBL has the capability to reach optimal solution in minimum time due to introduction of these opposite numbers. Oppositional based learning deals with opposite numbers, quasi-opposite numbers and Quasi-reflected numbers.

If $y$ is the real number between [ $p q, p r$ ] then the opposite number of $y$ may be defined as

$$
y_{0}=p q+p r-y
$$

Here $y_{0}$ is the opposite number of $y$

If $y$ is the real number between [ $p q, p r]$, then the quasi point, $y_{q 0}$ can be expressed as

$$
y_{q 0}=\operatorname{rand}\left(p c, \mathrm{y}_{0}\right)
$$

Here, $p c$ represents the midpoint of the interval [ $p q, p r]$; rand $\left(p c, y_{0}\right)$ is the random number which is distributed uniformly between $p c$ and $y_{0}$. A Similar principle can be applied for reflecting the quasi-opposite point $y_{q 0}$
If $y$ is the real number between [pc, $p r$ ], then the value of $y_{q r}$ can be defined as

$$
y_{q r}=\operatorname{rand}(p c, \mathrm{y})
$$

Here $y_{q r}$ is the quasi-reflected point.

The above-mentioned definitions can without much of a stretch may be reached out to larger dimensions.

\subsection{Implementation of OBL in GWO Algorithm}

Oppositional based learning technique is implemented in GWO algorithm in order to accelerating the convergence speed of GWO.QOGWO algorithm starts by choosing GWO variables such as search agent number, maximum iteration number. The population matrix $\mathrm{U}$ is generated according to the number of search agent and dimension of the problems. It is necessary to check the various constraints limits. The quasi-reflected sets are generated. After generating quasi-reflected set, the fitness function is calculated for initial population set and quasi-reflected set. On the basis of fitness, the best $U$ sets are sorted out and an updated matrix is formed. After that the minimum value of fitness function is calculated and the corresponding position of search agent is regarded as $\vec{G}_{\alpha}$. The position representing second and third minimum values of fitness function are considered as $\vec{G}_{\beta}$ and $\vec{G}_{\delta}$ respectively. Then $\vec{S}, \vec{P}$ and $\vec{S}$ is calculated using equation (18) and (19). The position of each search agent is updated using equation (20)-(25). Again random number is generated. If the random number is less than jumping rate, quasi reflected sets are generated using the updated set. The constraints limits are checked again. The fitness value for each updated search agent is calculated if all constraints limits are satisfied otherwise quasi-reflected sets are again generated. On the basis of fitness, the best $U$ sets are sorted out between updated set and quasi reflected set. The value of $\vec{G}_{\alpha}, \vec{G}_{\beta}, \vec{G}_{\delta}$ and $\vec{s}, \vec{P}$ and $\vec{S}$ are updated. The process is terminated if maximum number of iteration is reached. 


\subsection{Algorithms for Quasi Reflected based Initialization}

The steps are given below:

Randomly generate initial population $U$ in between maximum and minimum limits of decision variables and in between [ $\left[\begin{array}{ll}0 & 1\end{array}\right]$ generate a reflection weight $\mu$.

Generate Quasi-Reflected Sets (QRS) for each initially generated population set $\mathrm{U}$, using following procedure

For $\mathrm{e}=1: \mathrm{A}(\mathrm{A}=$ pop set $)$

For $\mathrm{f}=1: \mathrm{B}(\mathrm{B}=$ decision variable $)$

If $\mathrm{Ue}, \mathrm{f}<$ Median

$\mathrm{QRSe}, \mathrm{f}=\mathrm{Ue}, \mathrm{f}+(\text { Median- } \mathrm{Ue}, \mathrm{f})^{\star} \mu \mathrm{e} \% \% \%$

$($ Median $=\mathrm{Ue}, \mathrm{f}=(\mathrm{pq}+\mathrm{pr}) / 2)$

Else

QRSe,f $=$ Median $+(\text { Ue,f }- \text { Median })^{*} \mu \mathrm{e}$

end

end

end

Evaluate fitness value for QRS and total population.

Sort out best A individuals on the basis of their fitness.

Store the best population sets.

\subsection{Effect of Jumping Rate}

Quasi reflected sets have been used in GWO algorithm for accelerating the convergence speed. But it has been found that if quasi reflected sets are generated in every steps, it may increase the simulation time. Therefore, in order to optimize the computational time, a control parameter called jumping rate $\mathrm{r}^{38}$ has been used. It is a control parameter whose value is set by the user in order to skip the creation of quasi reflected set at certain generation. The effect of this parameter in QOGWO algorithm has been explained in the flow chart of section 4.4.

The pseudo code is given below

1. for $\mathrm{e}=1: \mathrm{A}(\mathrm{A}=$ population size $)$

2. if $\left(\operatorname{rand}_{\mathrm{e}}<\mathrm{J}_{\mathrm{r}}\right)$

3. In between $[0,1]$ generate reflection weight $\mu$ which is useful for determining the reflection amount of each fitness.

4. For $\mathrm{f}=1: \mathrm{B}(\mathrm{B}=$ desicion variable $)$

5. If $\mathrm{U}_{e, \mathrm{f}}<$ Median

6. $\mathrm{QRS}_{\mathrm{e}, \mathrm{f}}=\mathrm{U}_{\mathrm{e}, \mathrm{f}}+\left(\text { Median- } \mathrm{U}_{\mathrm{e}, \mathrm{f}}\right)^{*} \mu_{\mathrm{e}} \% \% \% \%$ (Median= $\left.\mathrm{U}_{\mathrm{e}, \mathrm{f}}=(p q+p r) / 2\right)$

7. Else

8. $\mathrm{QRS}_{\mathrm{e}, \mathrm{f}}=\mathrm{Median}+\left(\mathrm{U}_{\mathrm{e}, \mathrm{f}}-\mathrm{Median}\right)^{*} \mu_{\mathrm{e}}$

9. end

10. end

11. end

12. Evaluate fitness value for QRS, if selected by $\mathrm{J}_{\mathrm{r}}$

13. End

\subsection{Application of Quasi-oppositional Grey Wolf Optimizer Algorithm in ELD}

The flow chart of QOGWO algorithm is described in Figure 1 which shows the application of QOGWO algorithm in ELD problems. 


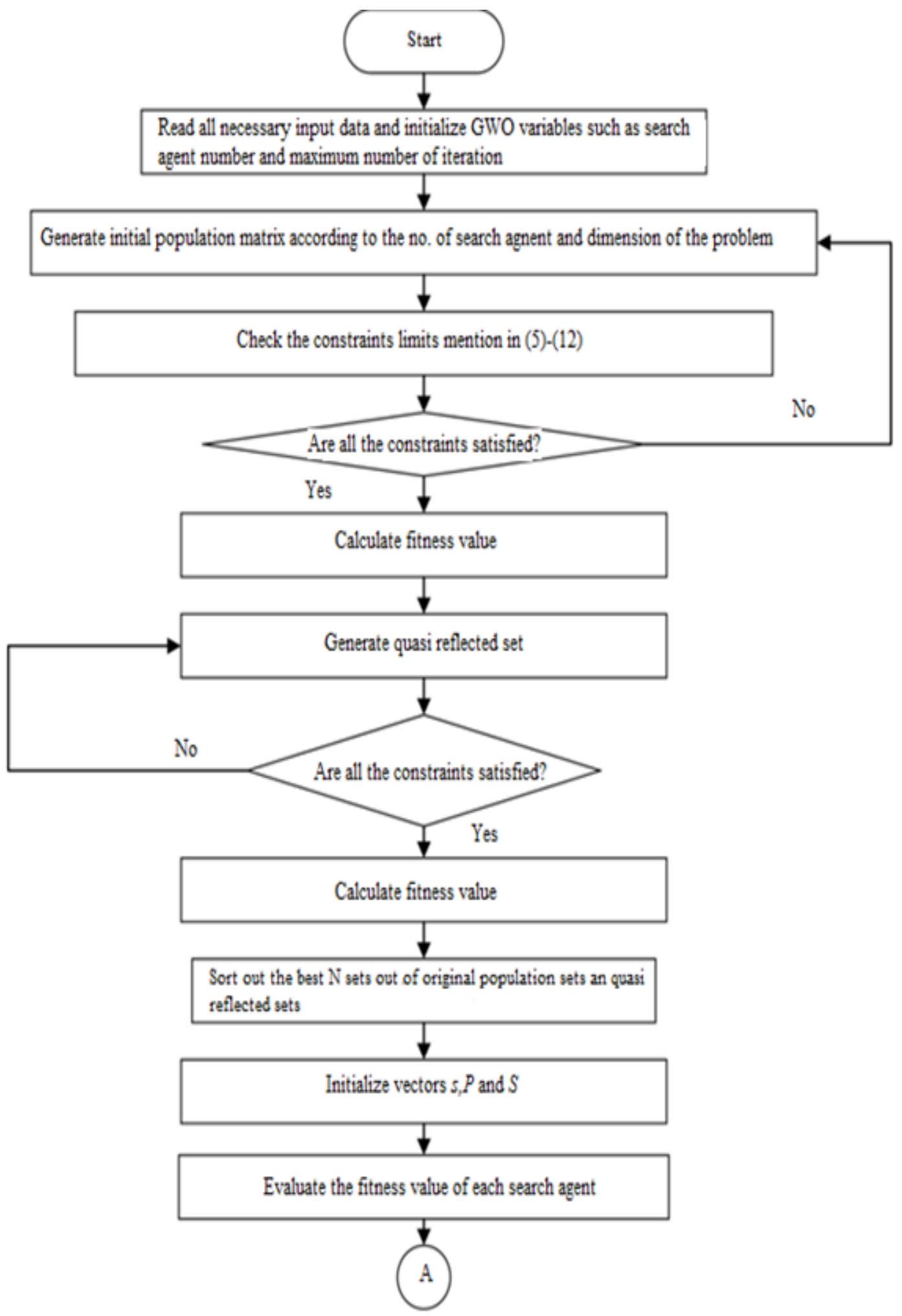




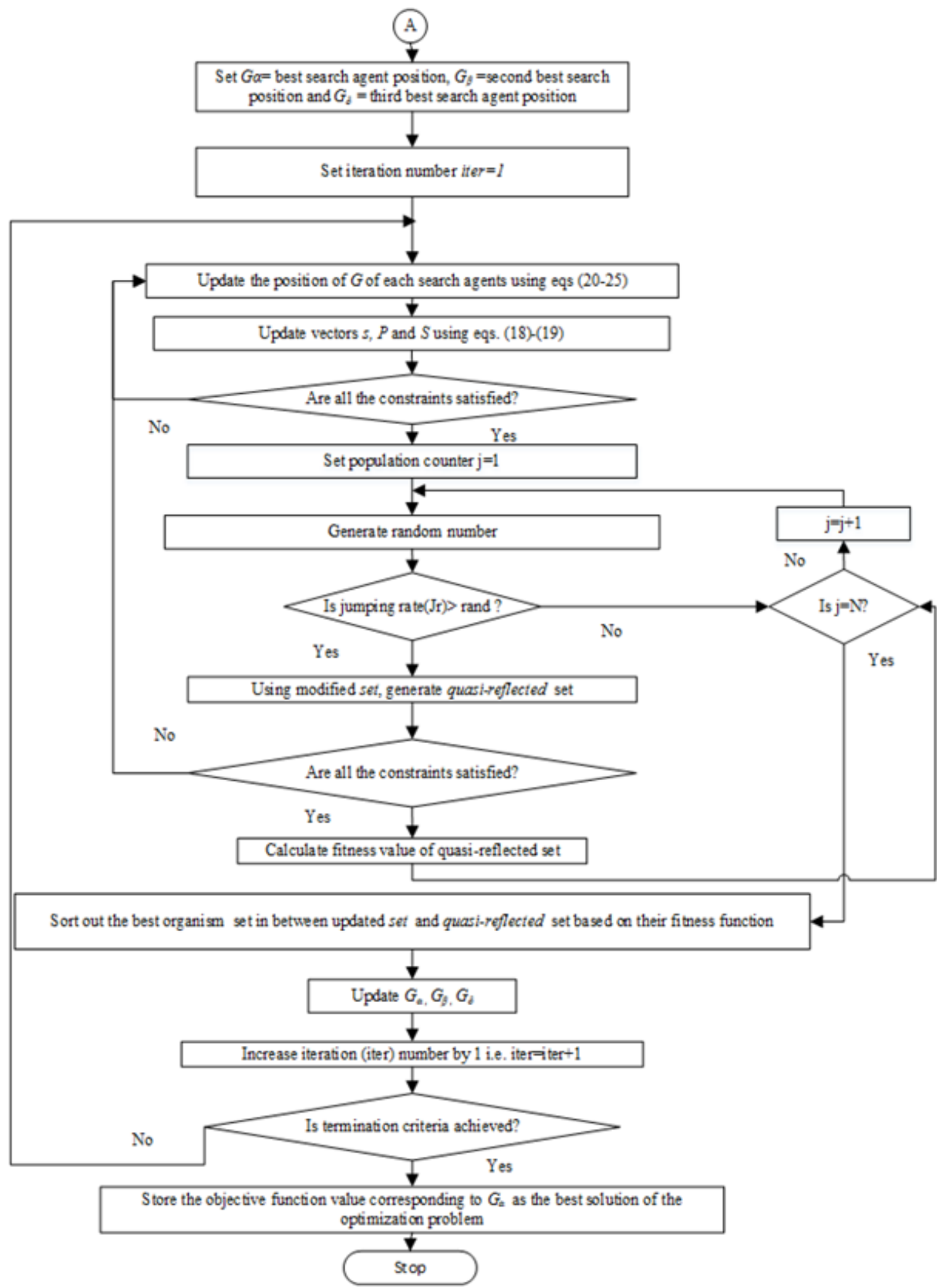

Figure 1. Flow chart of QOGWO algorithm applied to ELD problems. 


\section{Simulation Results}

The QOGWO algorithm has been applied to six different systems of ELD problem and the performance of this method is compared with different soft computing techniques like $\mathrm{GA}^{4}, \mathrm{PSO}^{7}, \mathrm{RCCO}^{11}, \mathrm{ORCCRO}^{12}, \mathrm{TLBO}^{14}$, $\mathrm{OIWO}^{32}, \mathrm{DE} / \mathrm{BBO}^{31}, \mathrm{EMA}^{15}, \mathrm{GWO}^{20}$ and so on. This algorithm has been coded in Matlab 9 and the program has been executed on a $2.40 \mathrm{GHz}$ core i3 computer with $2 \mathrm{~GB}$ RAM.

\subsection{Description of Systems}

\subsubsection{System 1}

A 3 generator ${ }^{20}$ system having load demand of $850 \mathrm{MW}$ and $1050 \mathrm{MW}$ is considered in this case. The transmission loss has not been considered here. The best results obtained by QGWO, $\mathrm{GWO}^{19}, \mathrm{GA}^{20}, \mathrm{PSO}^{20}, \mathrm{ABC}^{20}$ and $\mathrm{ALO}^{20}$ are presented in Table1 and Table 2. The cost convergence characteristics for 3 generators system are

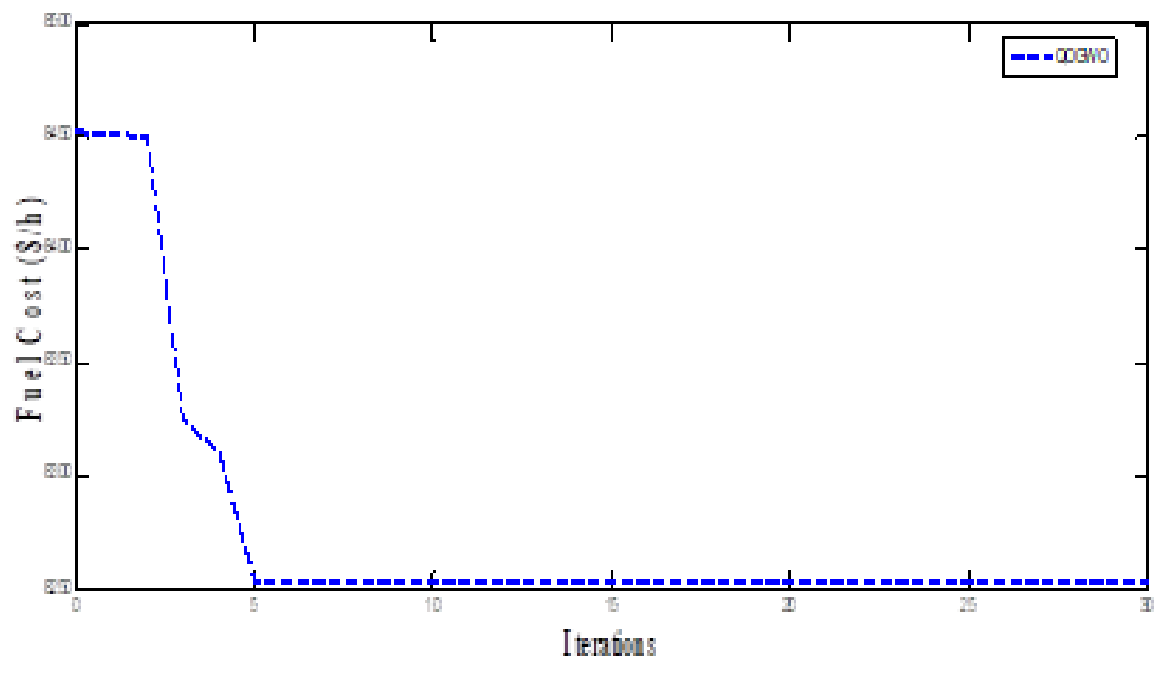

Figure 2. Convergence characteristics of system I (Load demand=850MW).

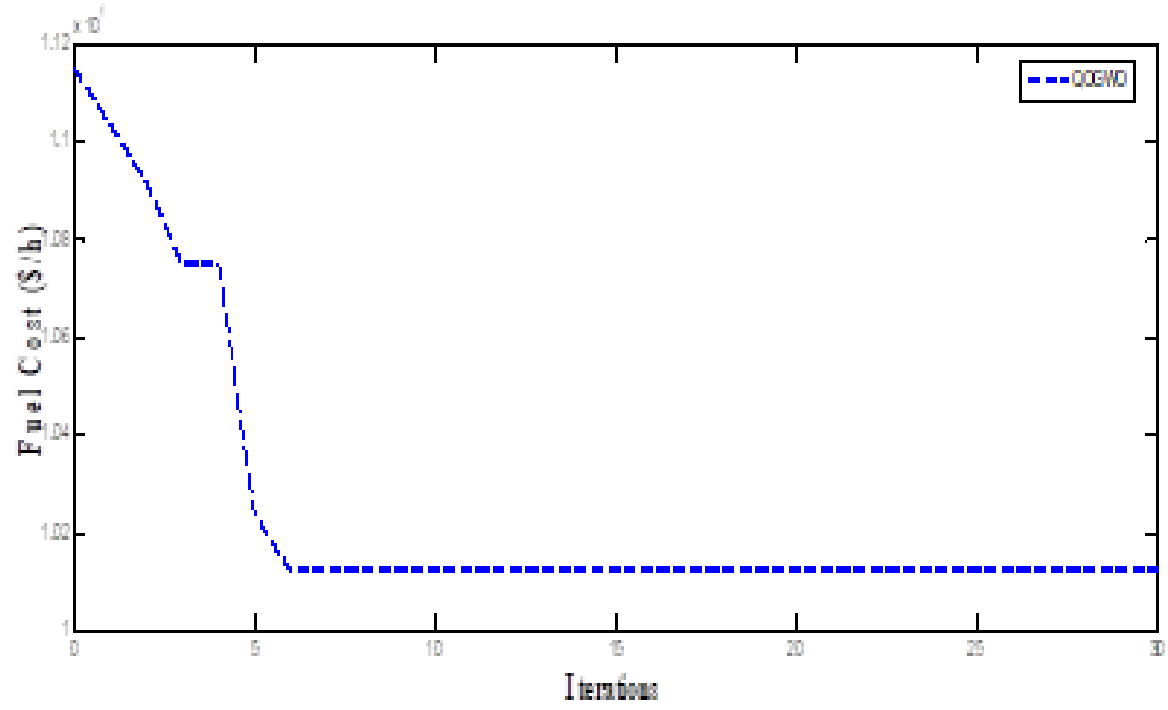

Figure 3. Convergence characteristics of system I (Load demand=1050 MW). 
Table 1. Power output for system I against minimum fuel price (Load demand=850 MW)

\begin{tabular}{|c|c|c|c|c|c|c|c|}
\hline Units & $\begin{array}{c}\text { Lambda } \\
\text { iteration }\end{array}$ & $\mathbf{G A}^{\mathbf{2 0}}$ & $\mathbf{P S O}^{\mathbf{2 0}}$ & $\mathbf{A B C}^{20}$ & $\mathbf{G W O}^{\mathbf{9}}$ & ALO $^{\mathbf{2 0}}$ & $\mathbf{Q O G W O}$ \\
\hline $\begin{array}{c}\mathrm{P}_{1} \\
\mathrm{MW}\end{array}$ & 382.258 & 382.2552 & 394.5243 & 300.266 & 300.5116 & 300.2673 & 300.2646 \\
\hline $\begin{array}{c}\mathrm{P}_{2} \\
\mathrm{MW}\end{array}$ & 127.419 & 127.4184 & 200 & 149.733 & 149.8107 & 149.733 & 149.7331 \\
\hline $\begin{array}{c}\mathrm{P}_{3} \\
\mathrm{MW}\end{array}$ & 340.323 & 340.3202 & 255.4756 & 400 & 399.6777 & 399.9997 & 400 \\
\hline $\begin{array}{c}\text { Fuel Cost } \\
(\$ / \mathrm{h})\end{array}$ & 8575.68 & 8575.64 & 8280.81 & 8253.1 & 8253.1053 & 8253.1052 & 8253.0629 \\
\hline
\end{tabular}

Table 2. Performance analysis of different methods for system I taken after 50trails (Load demand=850MW)

\begin{tabular}{|c|c|c|c|c|c|}
\hline Methods & Best cost $(\$ / h)$ & Mean $\operatorname{cost}(\$ / h)$ & Worst cost $(\$ / h)$ & $\begin{array}{c}\text { Time/iteration } \\
\text { (s) }\end{array}$ & $\begin{array}{l}\text { No of hits to best } \\
\text { Solution }\end{array}$ \\
\hline QOGWO & 8253.0629 & 8253.0865 & 8253.3579 & 12 & 46 \\
\hline $\begin{array}{l}\text { Lambda } \\
\text { iteration }\end{array}$ & NA & NA & NA & NA & NA \\
\hline $\mathrm{GA}^{20}$ & NA & NA & NA & NA & NA \\
\hline $\mathrm{PSO}^{20}$ & NA & NA & NA & NA & NA \\
\hline $\mathrm{ABC}^{20}$ & NA & NA & NA & NA & NA \\
\hline $\mathrm{GWO}^{19}$ & 8253.1053 & 8253.10558 & 8253.1061 & NA & NA \\
\hline $\mathrm{ALO}^{20}$ & 8253.1052 & NA & NA & NA & NA \\
\hline
\end{tabular}

Table 3. Power output for system I against minimum fuel price (Load demand=1050MW)

\begin{tabular}{|c|c|c|c|c|c|c|c|}
\hline Units & $\begin{array}{c}\text { Lambda } \\
\text { iteration }\end{array}$ & $\mathbf{G A}^{20}$ & $\mathbf{P S O}^{20}$ & $\mathbf{A B C}$ & $\mathbf{G W O}^{\mathbf{2 0}}$ & ALO $^{20}$ & QOGWO \\
\hline $\begin{array}{c}\mathrm{P}_{1} \\
\mathrm{MW}\end{array}$ & 487.5 & 487.498 & 492.699 & 492.6991 & 492.8465 & 492.6994 & 492.6991 \\
\hline $\begin{array}{c}\mathrm{P}_{2} \\
\mathrm{MW}\end{array}$ & 162.5 & 162.499 & 157.3 & 157.301 & 157.3927 & 158.1015 & 158.1015 \\
\hline $\begin{array}{c}\mathrm{P}_{3} \\
\mathrm{MW}\end{array}$ & 400 & 400 & 400 & 400 & 399.7609 & 399.1991 & 399.1993 \\
\hline $\begin{array}{c}\text { Fuel Cost } \\
(\$ / \mathrm{h})\end{array}$ & 10212.459 & 10212.44 & 10123.73 & 10123.73 & 10123.7196 & 10123.6949 & 10123.6931 \\
\hline
\end{tabular}


Table 4. Performance analysis of different methods for system I taken after 50trails (Load=1050MW)

\begin{tabular}{|c|c|c|c|c|c|}
\hline Methods & Best cost $\mathbf{( \$ \mathbf { h } )}$ & Mean $\operatorname{cost}(\mathbf{\$} / \mathbf{h})$ & Worst cost $\mathbf{( \$ \mathbf { h } )}$ & $\begin{array}{c}\text { Time/iteration } \\
(\mathbf{s})\end{array}$ & $\begin{array}{c}\text { No of hits to best } \\
\text { Solution }\end{array}$ \\
\hline QOGWO & 10123.6931 & 10123.69325 & 10123.6931 & 14 & 45 \\
\hline $\begin{array}{c}\text { Lambda } \\
\text { iteration }\end{array}$ & $\mathrm{NA}$ & $\mathrm{NA}$ & $\mathrm{NA}$ & $\mathrm{NA}$ & $\mathrm{NA}$ \\
\hline $\mathrm{GA}^{20}$ & $\mathrm{NA}$ & $\mathrm{NA}$ & $\mathrm{NA}$ & $\mathrm{NA}$ & $\mathrm{NA}$ \\
\hline $\mathrm{PSO}^{20}$ & $\mathrm{NA}$ & $\mathrm{NA}$ & $\mathrm{NA}$ & $\mathrm{NA}$ & NA \\
\hline $\mathrm{ABC}^{20}$ & $\mathrm{NA}$ & $\mathrm{NA}$ & $\mathrm{NA}$ & $\mathrm{NA}$ & NA \\
\hline $\mathrm{GWO}^{19}$ & 10123.72 & 10123.7347 & 10123.7392 & NA & NA \\
\hline $\mathrm{ALO}^{20}$ & 10123.6949 & 10123.71481 & 10123.7347 & NA & NA \\
\hline
\end{tabular}

shown in Figure 2 and Figure 3. Best, worst and average fuel price obtained by QOGWO, Lambda iteration ${ }^{20}$, $\mathrm{GA}^{20}, \mathrm{PSO}^{20}, \mathrm{ABC}^{20}, \mathrm{GWO}^{19}$ and $\mathrm{ALO}^{20}$ are shown in Table 3 and Table 4.

\subsubsection{System II}

In this system, a 5 generator system is considered. The Fuel price characteristic is quadratic in nature. The sys- tem demand is $730 \mathrm{MW}$. The data required for this case is taken from a paper written by Kamboj et al..$^{20}$ The results obtained by QOGWO, Lambda iteration ${ }^{20}, \mathrm{GA}^{20}, \mathrm{PSO}^{20}$, $\mathrm{APSO}^{20}, \mathrm{EP}^{20}, \mathrm{ABC}^{20}, \mathrm{GWO}^{20}$ and $\mathrm{ALO}^{20}$ are presented in Table 5. Minimum, Worst and Mean value obtained by Lambda iteration ${ }^{20}, \mathrm{GA}^{20}, \mathrm{PSO}^{20}, \mathrm{APSO}^{20}, \mathrm{EP}^{20}, \mathrm{ABC}^{20}$, $\mathrm{GWO}^{20}$ and $\mathrm{ALO}^{20}$ are displayed in Table 6. Figure 4 shows the fuel price convergence curve.

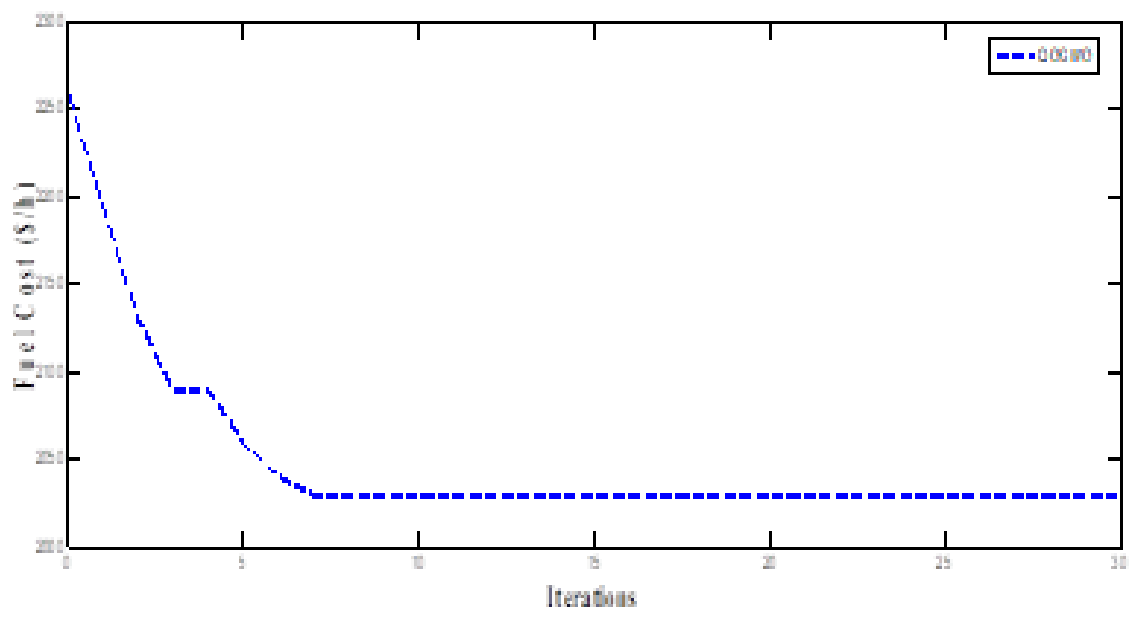

Figure 4. Convergence characteristics of system II. 
Table 5. Power output for system II against minimum fuel price (Load demand=730 MW)

\begin{tabular}{|c|c|c|c|c|c|}
\hline Methods & Best cost $(\$ / h)$ & Mean $\operatorname{cost}(\$ / h)$ & Worst cost $(\$ / h)$ & $\begin{array}{c}\text { Time/iteration } \\
\text { (s) }\end{array}$ & $\begin{array}{l}\text { No of hits to best } \\
\text { Solution }\end{array}$ \\
\hline QOGWO & 2029.6653 & 2029.6760 & 2029.9331 & 12.2 & 48 \\
\hline $\begin{array}{l}\text { Lambda } \\
\text { iteration }\end{array}$ & NA & NA & NA & NA & NA \\
\hline $\mathrm{GA}^{20}$ & NA & NA & NA & NA & NA \\
\hline $\mathrm{PSO}^{20}$ & NA & NA & NA & NA & NA \\
\hline $\mathrm{APSO}^{20}$ & NA & NA & NA & NA & NA \\
\hline $\mathrm{EP}^{20}$ & NA & NA & NA & NA & NA \\
\hline $\mathrm{ABC}^{20}$ & NA & NA & NA & NA & NA \\
\hline $\mathrm{GWO}^{20}$ & 2030.0713 & 2084.4342 & 2161.4967 & NA & NA \\
\hline $\mathrm{ALO}^{20}$ & 2029.6669 & 2055.1717 & 2089.3825 & NA & NA \\
\hline
\end{tabular}

Table 6. Performance analysis of different methods for system II taken after 50trails (Load demand=730 MW)

\begin{tabular}{|c|c|c|c|c|c|c|c|c|c|c|}
\hline Units & GA $^{33}$ & PSO $^{33}$ & IPSO $^{33}$ & $\begin{array}{c}\text { SOH- } \\
\text { PSO }^{33}\end{array}$ & DE $^{33}$ & BFO $^{33}$ & CRO $^{33}$ & $\begin{array}{c}\text { HCRO- } \\
\text { DE }^{33}\end{array}$ & GWO & QOGWO \\
\hline $\begin{array}{c}\mathrm{P}_{1} \\
(\mathrm{MW})\end{array}$ & 462.0444 & 447.5823 & 440.5711 & 438.2100 & 448.5181 & 449.4600 & 447.9314 & 447.4021 & 447.5544 & 447.3992 \\
\hline $\begin{array}{c}\mathrm{P}_{2} \\
(\mathrm{MW})\end{array}$ & 189.4456 & 172.8387 & 179.8365 & 172.5800 & 173.3686 & 172.8800 & 173.5548 & 173.2407 & 173.1587 & 173.2409 \\
\hline $\begin{array}{c}\mathrm{P}_{3} \\
(\mathrm{MW})\end{array}$ & 254.8535 & 261.3300 & 261.3798 & 257.4200 & 263.0535 & 263.4100 & 262.9452 & 263.3812 & 263.4457 & 263.3816 \\
\hline $\begin{array}{c}\mathrm{P}_{4} \\
(\mathrm{MW})\end{array}$ & 127.4296 & 138.6812 & 131.9134 & 141.0900 & 138.6733 & 143.4900 & 138.8521 & 138.9774 & 138.8615 & 138.9797 \\
\hline
\end{tabular}


Table 6 Continued

\begin{tabular}{|c|c|c|c|c|c|c|c|c|c|c|}
\hline $\begin{array}{c}\mathrm{P}_{5} \\
(\mathrm{MW})\end{array}$ & 151.5388 & 169.6781 & 170.9823 & 179.3700 & 165.4849 & 164.9100 & 165.3046 & 165.3897 & 165.4779 & 165.3918 \\
\hline $\begin{array}{c}\mathrm{P}_{6} \\
(\mathrm{MW})\end{array}$ & 90.7150 & 74.8963 & 90.8241 & 86.8800 & 86.3543 & 81.2520 & 86.8575 & 87.0538 & 86.9499 & 87.0516 \\
\hline $\begin{array}{c}\text { Total } \\
\text { Power } \\
(\mathrm{MW})\end{array}$ & NA & NA & NA & NA & NA & NA & NA & NA & 1275.4400 & 1275.4400 \\
\hline $\begin{array}{c}\text { Power } \\
\text { loss } \\
(\mathrm{MW})\end{array}$ & 13.0260 & 13.0066 & 12.5480 & 12.5500 & 12.4527 & 12.4020 & 12.4456 & 12.4449 & 12.4400 & 12.4400 \\
\hline $\begin{array}{l}\text { Fuel } \\
\text { cost } \\
(\$ / h)\end{array}$ & 15457.960 & 15450.140 & 15444.000 & 15446.0200 & 15443.105 & 15443.8497 & 15443.080 & 15443.075 & 15443.0743 & 15443.0738 \\
\hline
\end{tabular}

\subsubsection{System III}

A 6 generators system having the system demand of 1263 MW is considered in this case. The prohibited zones, ramp rate limit and transmission loss are also considered here. Necessary data for this system is taken from a paper written by Roy et al. ${ }^{33}$ The results obtained by QOGWO,
GWO, $\mathrm{GA}^{33}, \mathrm{PSO}^{33}, \mathrm{IPSO}^{33}, \mathrm{SOH}-\mathrm{PSO}^{33}, \mathrm{DE}^{33}, \mathrm{BFO}^{33}$, $\mathrm{CRO}^{33}$, and HCRO-DE ${ }^{33}$ are displayed in Table 7. Figure 5 represents the cost convergence curve for 6-generator system. Minimum, worst and average fuel cost obtained with QOGWO, GWO, HCRO-DE ${ }^{33}, \mathrm{CRO}^{33}, \mathrm{DE}^{33}, \mathrm{BFO}^{33}$, $\mathrm{SOH}^{-\mathrm{PSO}^{33}}{ }^{3} \mathrm{IPSO}^{33}, \mathrm{NAPSO}^{33}$, IPSO-TVAC ${ }^{33}$, and $\mathrm{PSO}^{33}$ are shown in Table 8.

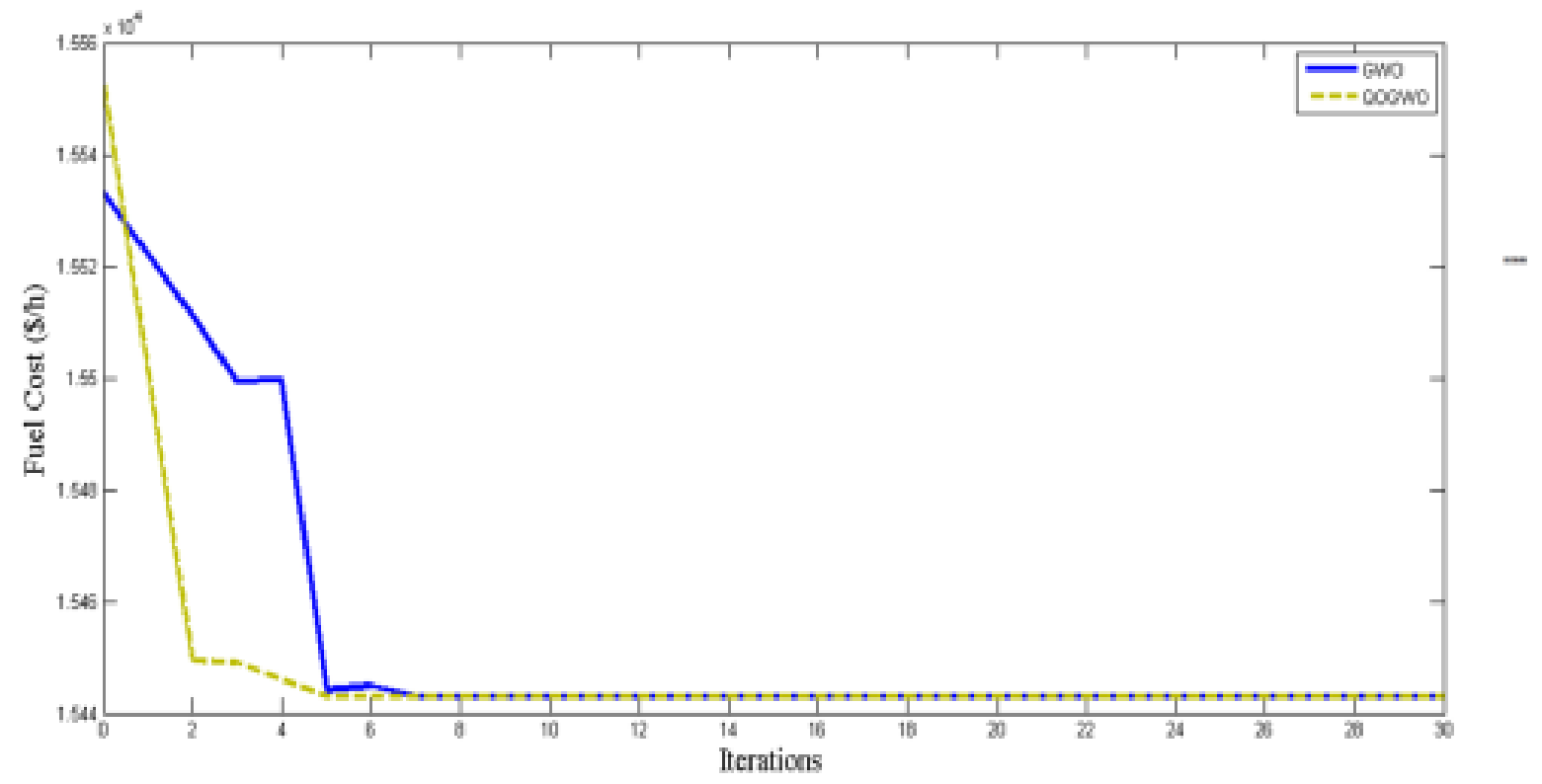

Figure 5. Convergence characteristics of system III. 
Table 7. Power output for system III with considering transmission loss ( $\mathrm{PD}=1263 \mathrm{MW})$

\begin{tabular}{|c|c|c|c|c|c|c|c|c|c|}
\hline Units & $\begin{array}{c}\text { Lambda } \\
\text { iteration }^{20}\end{array}$ & $\mathrm{GA}^{20}$ & $\mathrm{PSO}^{20}$ & $\mathrm{APSO}^{20}$ & $\mathbf{E P}^{20}$ & $\mathrm{ABC}^{20}$ & $\mathrm{GWO}^{20}$ & $\mathrm{ALO}^{20}$ & QOGWO \\
\hline $\begin{array}{c}\mathrm{P}_{1} \\
\mathrm{MW}\end{array}$ & 218.028 & 218.0184 & 229.5195 & 225.3845 & 229.803 & 229.5247 & 229.5534 & 29.5196 & 229.5196 \\
\hline $\begin{array}{c}\mathrm{P}_{2} \\
\mathrm{MW}\end{array}$ & 109.014 & 109.0092 & 125 & 113.02 & 101.5736 & 102.0669 & 102.3639 & 102.988 & 102.9911 \\
\hline $\begin{array}{c}\mathrm{P}_{3} \\
\mathrm{MW}\end{array}$ & 147.535 & 147.5227 & 175 & 109.4146 & 113.7999 & 113.4005 & 113.2209 & 112.6765 & 112.6735 \\
\hline $\begin{array}{c}\mathrm{P}_{4} \\
\mathrm{MW}\end{array}$ & 28.38 & 28.37844 & 75 & 73.11176 & 75 & 75 & 74.9183 & 75 & 75 \\
\hline $\begin{array}{c}\mathrm{P}_{5} \\
\mathrm{MW}\end{array}$ & 272.042 & 227.0275 & 125.4804 & 209.0692 & 209.8235 & 210.0079 & 209.9434 & 209.8159 & 209.8158 \\
\hline $\begin{array}{l}\text { Fuel } \\
\text { Cost } \\
(\$ / h)\end{array}$ & 2412.709 & 2412.538 & 2252.572 & 2140.97 & 2030.673 & 2030.259 & 2030.0713 & 2029.6669 & 2029.6653 \\
\hline
\end{tabular}

Table 8. Performance analysis of different methods for system III taken after 50 trails (Load demand=1263 MW)

\begin{tabular}{|c|c|c|c|c|c|}
\hline \multirow{2}{*}{ Methods } & \multicolumn{3}{|c|}{ Generation $\operatorname{cost}(\$ / h)$} & \multirow{2}{*}{ Time (s) } & \multirow{2}{*}{$\begin{array}{c}\text { Success rate } \\
(\%)\end{array}$} \\
\hline & $\operatorname{Max} . \operatorname{Cost}(\$ / h)$ & Min. (\$/h) & Average $(\$ / h)$ & & \\
\hline QOGWO & 15443.0738 & 15443.0738 & 15443.0738 & 3.8 & 100 \\
\hline GWO & 15443.0857 & 15443.0743 & 15443.0747 & 4 & 96 \\
\hline HCRO-DE ${ }^{33}$ & 15443.916 & 15443.075 & 15443.182 & 4.17 & 97 \\
\hline $\mathrm{CRO}^{33}$ & 15446.753 & 15443.080 & 15444.135 & 4.96 & 82 \\
\hline $\mathrm{DE}^{33}$ & 15448.361 & 15443.105 & 15445.287 & 4.43 & 76 \\
\hline $\mathrm{BFO}^{33}$ & NA & 15443.8497 & 15446.9538 & NA & NA \\
\hline $\mathrm{SOH}_{-} \mathrm{PSO}^{33}$ & 15609.64 & 15446.02 & 15497.35 & 6.33 & NA \\
\hline $\mathrm{IPSO}^{33}$ & NA & 15444.00 & 15446.30 & NA & NA \\
\hline $\mathrm{NAPSO}^{33}$ & 15443.7657 & 15443.7656 & 15443.7657 & NA & NA \\
\hline IPSO-TVAC $^{33}$ & 15445.114 & 15443.063 & 15443.582 & NA & NA \\
\hline $\mathrm{PSO}^{33}$ & 15492.0 & 15450.14 & 15454.00 & 6 & NA \\
\hline
\end{tabular}




\subsubsection{System IV}

A 38 generators unit, ${ }^{13}$ with quadratic fuel cost function is considered in this case. The system demand is 6000MW. The transmission loss has not been considered for this case. The best result obtained by QOGWO method is shown in Table 9. The average, worst and best fuel price obtained by QOGWO, GWO, $\mathrm{BBO}^{13}, \mathrm{DE} / \mathrm{BBO}^{26}$ and $\mathrm{RCCRO}^{11}$ is shown in Table 10. Figure 6 presents the convergence characteristic for 38 generators system.

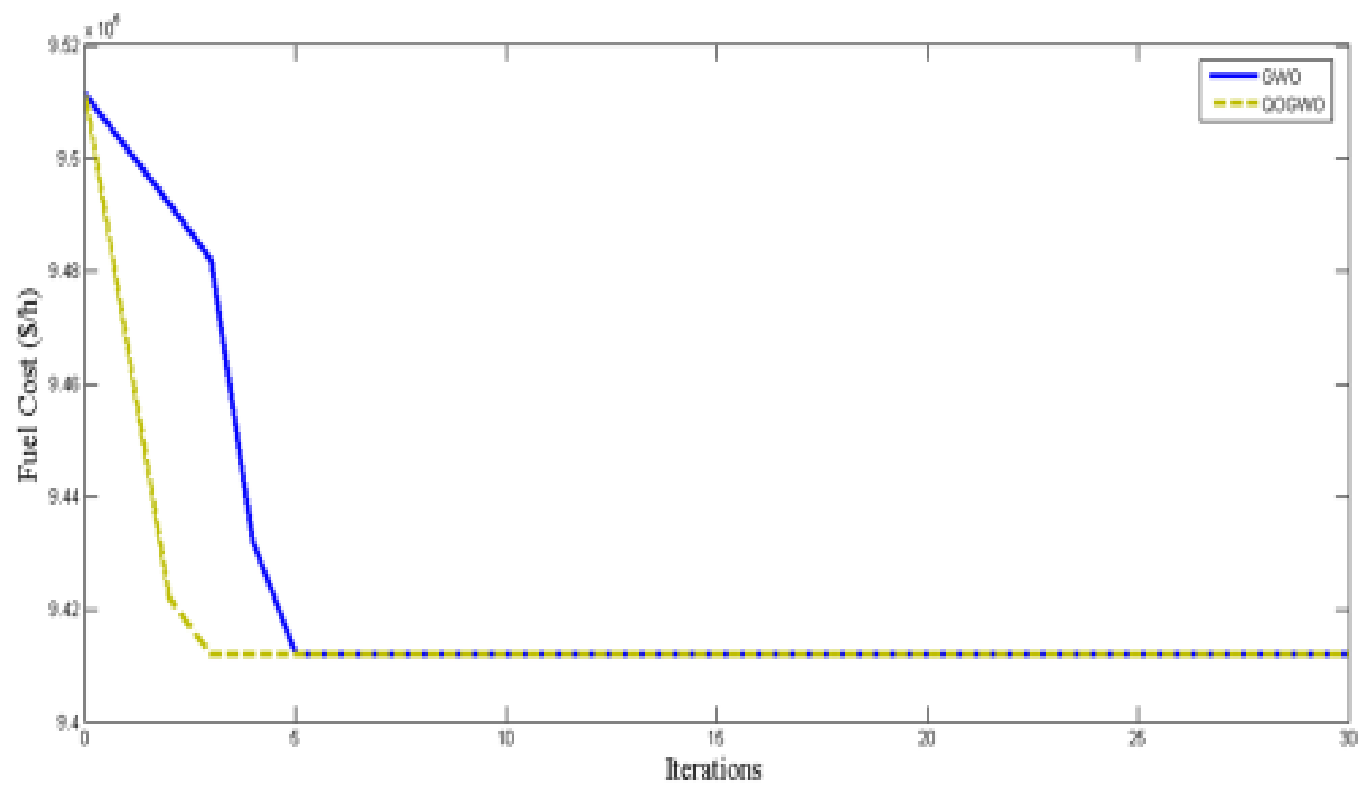

Figure 6. Fuel price convergence characteristics of system IV.

Table 9. Power output for system IV against minimum fuel price ( $\mathrm{PD}=6000 \mathrm{MW})$

\begin{tabular}{|c|c|c|c|c|c|c|c|}
\hline \multicolumn{4}{|c|}{ GWO } & \multicolumn{4}{|c|}{ QOGWO } \\
\hline Units & $\begin{array}{c}\text { Power } \\
\text { outputs } \\
\text { (MW) }\end{array}$ & Units & $\begin{array}{c}\text { Power } \\
\text { outputs } \\
\text { (MW) }\end{array}$ & Units & $\begin{array}{c}\text { Power } \\
\text { outputs } \\
\text { (MW) }\end{array}$ & Units & $\begin{array}{c}\text { Power } \\
\text { outputs } \\
(\mathrm{MW})\end{array}$ \\
\hline 1 & 426.283482 & 21 & 271.999760 & 1 & 426.606400 & 21 & 272.000000 \\
\hline 2 & 428.325554 & 22 & 259.999546 & 2 & 426.714400 & 22 & 260.000000 \\
\hline 3 & 428.279991 & 23 & 130.237235 & 3 & 429.643300 & 23 & 130.655800 \\
\hline 4 & 428.837848 & 24 & 10.001852 & 4 & 429.707600 & 24 & 10.001140 \\
\hline 5 & 428.628224 & 25 & 113.893154 & 5 & 429.631000 & 25 & 113.246300 \\
\hline 6 & 429.016029 & 26 & 88.381782 & 6 & 429.652300 & 26 & 88.027270 \\
\hline
\end{tabular}


Table 9 Continued

\begin{tabular}{|c|c|c|c|c|c|c|c|}
\hline 7 & 429.160972 & 27 & 37.490037 & 7 & 429.588400 & 27 & 37.486970 \\
\hline 8 & 430.380091 & 28 & 20.000012 & 8 & 429.749100 & 28 & 20.000000 \\
\hline 9 & 114.006472 & 29 & 20.000028 & 9 & 114.000000 & 29 & 20.000000 \\
\hline 10 & 114.000321 & 30 & 20.000089 & 10 & 114.000000 & 30 & 20.000000 \\
\hline 11 & 120.666869 & 31 & 20.000000 & 11 & 119.796600 & 31 & 20.000000 \\
\hline 12 & 127.474273 & 32 & 20.000019 & 12 & 127.073900 & 32 & 20.000000 \\
\hline 13 & 110.000107 & 33 & 25.000039 & 13 & 110.000000 & 33 & 25.000000 \\
\hline 14 & 90.000014 & 34 & 18.000010 & 14 & 90.000000 & 34 & 18.000000 \\
\hline 15 & 82.000055 & 35 & 8.000032 & 15 & 82.000000 & 35 & 8.000002 \\
\hline 16 & 120.000142 & 36 & 25.000045 & 16 & 120.000000 & 36 & 25.000000 \\
\hline 17 & 159.969453 & 37 & 21.811972 & 17 & 159.574400 & 37 & 21.773290 \\
\hline 18 & 65.000006 & 38 & 21.154546 & 18 & 65.000000 & 38 & 21.071580 \\
\hline 19 & 65.000035 & \multirow{2}{*}{\multicolumn{2}{|c|}{$\begin{array}{c}\operatorname{Cost}(\$ / h)= \\
9411940.8691023886\end{array}$}} & 19 & 65.000000 & \multirow{2}{*}{\multicolumn{2}{|c|}{$\operatorname{Cost}(\$ / h)=9411935.7244$}} \\
\hline 20 & 271.999905 & & & 20 & 272.0000 & & \\
\hline
\end{tabular}

Table 10. Performance analysis of different methods for system IV taken after 50trails (Load demand=6000 MW)

\begin{tabular}{|c|c|c|c|c|c|}
\hline \multirow{2}{*}{ Methods } & \multicolumn{3}{|c|}{ Generation $\operatorname{cost}(\$ / h)$} & \multirow{2}{*}{$\begin{array}{c}\text { Time/ } \\
\text { iteration, (s) }\end{array}$} & \multirow{2}{*}{$\begin{array}{l}\text { No of hits to } \\
\text { minimum } \\
\text { Solution }\end{array}$} \\
\hline & $\operatorname{Max} \cdot \operatorname{cost}(\$ / \mathbf{h})$ & $\operatorname{Min} . \cos t(\$ / h)$ & Average cost $(\$ / h)$ & & \\
\hline QOGWO & 9411935.7244 & 9411935.7244 & 9411935.7244 & 0.49 & 50 \\
\hline GWO & 9411940.8691023 & 9411940.8691023 & 9411940.8691023 & 0.56 & 50 \\
\hline $\mathrm{BBO}^{13}$ & 9417658.7520243911 & 9417633.6376443729 & 9417638.15823277617 & 12.12 & 41 \\
\hline $\mathrm{DE} / \mathrm{BBO}^{31}$ & 9417250.83217432 & 9417235.786391673 & 9417237.2909699377 & 17.5 & 45 \\
\hline $\mathrm{RCCRO}^{11}$ & 9412404.2774250172 & 9412404.2774250172 & 9412404.2774250172 & 0.65 & 50 \\
\hline
\end{tabular}




\subsubsection{System $V$}

An 110 unit $^{32}$ system with quadratic fuel price has been considered here. The system demand is $15000 \mathrm{MW}$. The best fuel price obtained by QGWO and GWO techniques is displayed in Table 11. Figure 7 represents the convergence curve of 110 generator system. Average, maximum and best fuel cost acquired by QOGWO, GWO, OIWO ${ }^{32}$, $\mathrm{ORCCRO}^{32}, \mathrm{SAB}^{32}, \mathrm{SAF}^{32}, \mathrm{BBO}^{13}, \mathrm{DE} / \mathrm{BBO}^{31}$ and $\mathrm{SA}^{32}$ for 50 trails are shown in Table 12.

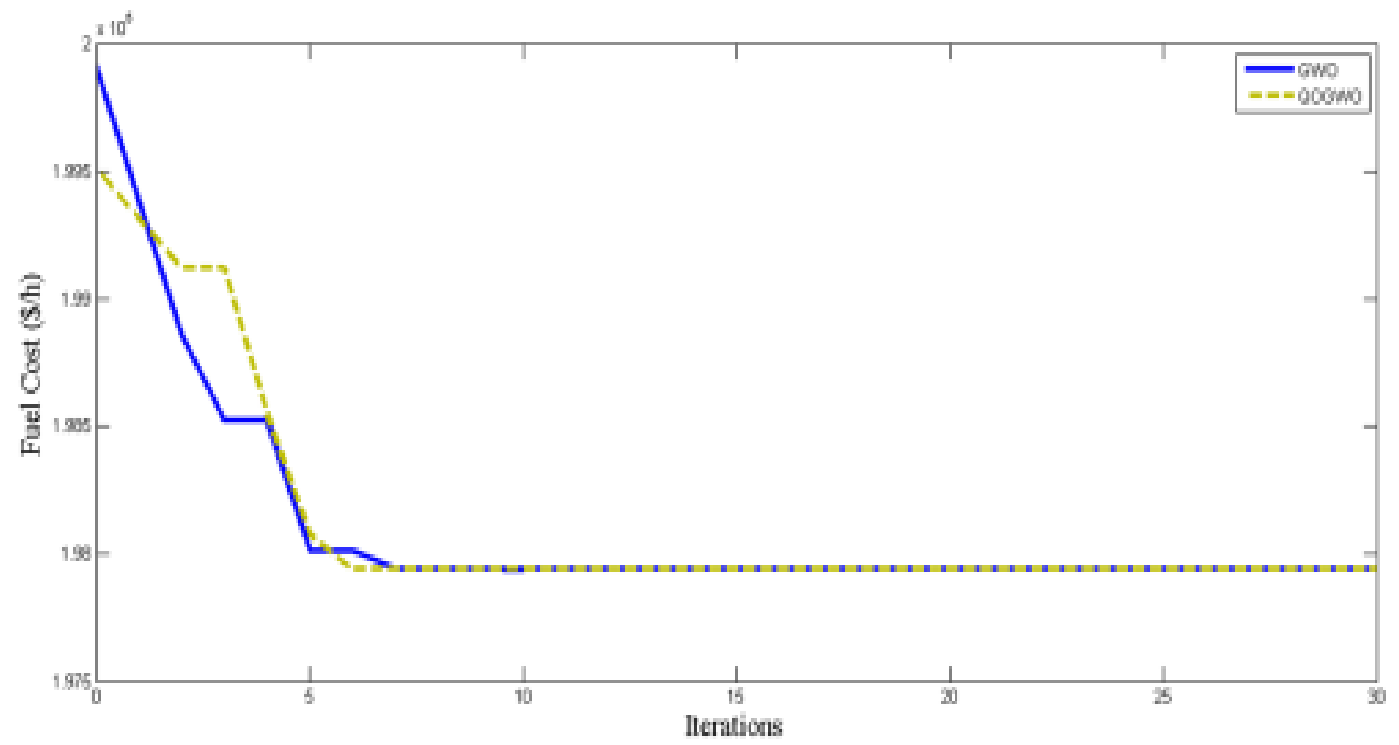

Figure 7. Cost Convergence characteristics for system V.

Table 12. Performance analysis of different methods for system V taken after 50 trails

\begin{tabular}{|c|c|c|c|c|c|c|c|c|c|c|c|}
\hline \multicolumn{9}{|c|}{ GWO } & \multicolumn{3}{c|}{ QGWO } \\
\hline $\begin{array}{c}\text { Un- } \\
\text { its }\end{array}$ & $\begin{array}{c}\text { Power } \\
\text { outputs } \\
(\mathbf{M W})\end{array}$ & $\begin{array}{c}\text { Un- } \\
\text { its }\end{array}$ & $\begin{array}{c}\text { Power } \\
\text { outputs } \\
(\mathbf{M W})\end{array}$ & $\begin{array}{c}\text { Un- } \\
\text { its }\end{array}$ & $\begin{array}{c}\text { Power } \\
\text { outputs } \\
(\mathbf{M W})\end{array}$ & $\begin{array}{c}\text { Un- } \\
\text { its }\end{array}$ & $\begin{array}{c}\text { Power } \\
\text { outputs } \\
(\mathbf{M W})\end{array}$ & $\begin{array}{c}\text { Un- } \\
\text { its }\end{array}$ & $\begin{array}{c}\text { Power } \\
\text { outputs } \\
(\mathbf{M W})\end{array}$ & $\begin{array}{c}\text { Un- } \\
\text { its }\end{array}$ & $\begin{array}{c}\text { Power } \\
\text { outputs } \\
(\text { MW })\end{array}$ \\
\hline 1 & 2.405370 & 41 & 146.289200 & 81 & 10.001510 & 1 & 2.402484 & 41 & 154.473600 & 81 & 10.000120 \\
\hline 2 & 2.4000000 & 42 & 219.999400 & 82 & 12.684820 & 2 & 2.407023 & 42 & 219.980400 & 82 & 12.014320 \\
\hline 3 & 2.4000000 & 43 & 440.000000 & 83 & 20.252710 & 3 & 2.400128 & 43 & 439.985700 & 83 & 20.000590 \\
\hline 4 & 2.404406 & 44 & 559.997400 & 84 & 199.997400 & 4 & 2.400003 & 44 & 559.999400 & 84 & 199.991600 \\
\hline 5 & 2.400186 & 45 & 659.996800 & 85 & 325.000000 & 5 & 2.400000 & 45 & 659.997200 & 85 & 324.657300 \\
\hline 6 & 4.002318 & 46 & 613.522500 & 86 & 439.997800 & 6 & 4.000008 & 46 & 608.893500 & 86 & 439.999800 \\
\hline 7 & 4.002490 & 47 & 5.4000560 & 87 & 12.468040 & 7 & 4.000211 & 47 & 5.407616 & 87 & 34.991320 \\
\hline 8 & 4.042332 & 48 & 5.400046 & 88 & 20.044090 & 8 & 4.000002 & 48 & 5.400769 & 88 & 20.046580 \\
\hline
\end{tabular}


Table 11 Continued

\begin{tabular}{|c|c|c|c|c|c|c|c|c|c|c|c|}
\hline 9 & 4.000069 & 49 & 8.402872 & 89 & 59.389670 & 9 & 4.000001 & 49 & 8.400001 & 89 & 73.331440 \\
\hline 10 & 63.848770 & 50 & 8.400017 & 90 & 92.689530 & 10 & 75.843070 & 50 & 8.400000 & 90 & 85.298620 \\
\hline 11 & 64.459060 & 51 & 8.400010 & 91 & 62.302940 & 11 & 76.000000 & 51 & 8.408124 & 91 & 55.543110 \\
\hline 12 & 40.363620 & 52 & 12.002930 & 92 & 99.946830 & 12 & 34.222160 & 52 & 12.005930 & 92 & 94.715960 \\
\hline 13 & 50.198360 & 53 & 12.000000 & 93 & 439.997200 & 13 & 55.623220 & 53 & 12.000020 & 93 & 439.999800 \\
\hline 14 & 25.001110 & 54 & 12.000000 & 94 & 499.943800 & 14 & 25.000700 & 54 & 12.000030 & 94 & 499.959000 \\
\hline 15 & 25.000110 & 55 & 12.000020 & 95 & 599.999900 & 15 & 25.013820 & 55 & 12.000940 & 95 & 599.962000 \\
\hline 16 & 25.000060 & 56 & 25.201300 & 96 & 472.196400 & 16 & 25.000390 & 56 & 25.238840 & 96 & 486.265200 \\
\hline 17 & 154.998400 & 57 & 25.317330 & 97 & 3.603280 & 17 & 154.999700 & 57 & 25.367110 & 97 & 3.600004 \\
\hline 18 & 155.000000 & 58 & 35.000000 & 98 & 3.600005 & 18 & 154.998800 & 58 & 35.006200 & 98 & 3.600001 \\
\hline 19 & 155.000000 & 59 & 35.007430 & 99 & 4.401353 & 19 & 154.999200 & 59 & 35.036350 & 99 & 4.400013 \\
\hline 20 & 154.998600 & 60 & 45.000000 & 100 & 4.400014 & 20 & 154.928500 & 60 & 45.000420 & 100 & 4.400000 \\
\hline 21 & 68.900010 & 61 & 45.016410 & 101 & 10.092860 & 21 & 68.900000 & 61 & 45.000920 & 101 & 10.000290 \\
\hline 22 & 68.900060 & 62 & 45.003140 & 102 & 10.000290 & 22 & 68.900100 & 62 & 45.000010 & 102 & 10.028160 \\
\hline 23 & 68.907460 & 63 & 184.892100 & 103 & 20.000010 & 23 & 68.900030 & 63 & 184.980800 & 103 & 20.003130 \\
\hline 24 & 349.987400 & 64 & 184.875900 & 104 & 20.000160 & 24 & 349.993900 & 64 & 185.000000 & 104 & 20.000070 \\
\hline 25 & 399.990800 & 65 & 184.981900 & 105 & 40.001650 & 25 & 399.996100 & 65 & 184.956800 & 105 & 40.000030 \\
\hline 26 & 399.999500 & 66 & 184.944100 & 106 & 40.000020 & 26 & 399.999200 & 66 & 184.810900 & 106 & 40.000000 \\
\hline 27 & 499.987400 & 67 & 70.000730 & 107 & 50.000540 & 27 & 499.979500 & 67 & 70.000470 & 107 & 50.000010 \\
\hline 28 & 499.958900 & 68 & 70.000040 & 108 & 30.015350 & 28 & 499.989800 & 68 & 70.003380 & 108 & 30.018690 \\
\hline 29 & 199.999000 & 69 & 70.004050 & 109 & 40.000200 & 29 & 199.999900 & 69 & 70.022430 & 109 & 40.000250 \\
\hline 30 & 99.998570 & 70 & 359.945600 & 110 & 20.027320 & 30 & 100.000000 & 70 & 359.940300 & 110 & 20.000710 \\
\hline
\end{tabular}


Table 11 Continued

\begin{tabular}{|c|c|c|c|c|c|c|c|c|c|}
\hline 31 & 10.000000 & 71 & 399.999200 & \multirow{10}{*}{$\begin{array}{c}\operatorname{Cost}(\$ / h)= \\
197938.7729\end{array}$} & 31 & 10.000510 & 71 & 399.999700 & \multirow{10}{*}{$\begin{array}{c}\operatorname{Cost}(\$ / h)= \\
197938.2294\end{array}$} \\
\hline 32 & 19.799020 & 72 & 399.699200 & & 32 & 19.998330 & 72 & 399.999900 & \\
\hline 33 & 79.632870 & 73 & 102.031000 & & 33 & 79.999930 & 73 & 100.613000 & \\
\hline 34 & 249.814200 & 74 & 194.395900 & & 34 & 249.998300 & 74 & 187.970900 & \\
\hline 35 & 360.000000 & 75 & 89.999910 & & 35 & 359.982800 & 75 & 89.986560 & \\
\hline 36 & 399.998200 & 76 & 49.989840 & & 36 & 399.999800 & 76 & 49.789200 & \\
\hline 37 & 39.990400 & 77 & 160.000600 & & 37 & 40.000000 & 77 & 49.789200 & \\
\hline 38 & 69.999040 & 78 & 304.321500 & & 38 & 69.996980 & 78 & 290.147800 & \\
\hline 39 & 99.954810 & 79 & 182.017000 & & 39 & 99.976990 & 79 & 170.920500 & \\
\hline 40 & 119.093400 & 80 & 118.653400 & & 40 & 119.968700 & 80 & 93.251880 & \\
\hline
\end{tabular}

Table 12. Performance analysis of different methods for system V taken after 50 trails

\begin{tabular}{|c|c|c|c|c|c|}
\hline \multirow{2}{*}{ Methods } & \multicolumn{3}{|c|}{ Generation $\operatorname{cost}(\$ / \mathrm{h})$} & \multirow{2}{*}{ Time (s) } & \multirow{2}{*}{$\begin{array}{l}\text { No of hits to } \\
\text { minimum } \\
\text { Solution }\end{array}$} \\
\hline & $\operatorname{Max} \cdot \operatorname{cost}(\$ / h)$ & $\operatorname{Min} . \operatorname{cost}(\$ / h)$ & Average cost $(\$ / h)$ & & \\
\hline QOGWO & 197938.2294 & 197938.2294 & 197938.2294 & 21 & 50 \\
\hline GWO & 197938.7729 & 197938.7729 & 197938.7729 & 22 & 50 \\
\hline $\mathrm{OIWO}^{32}$ & 197989.93 & 197989.14 & 197989.14 & 31 & 46 \\
\hline $\mathrm{ORCCRO}^{12}$ & 198016.89 & 198016.29 & 198016.32 & 45 & 48 \\
\hline $\mathrm{SAB}^{32}$ & NA & 206912.9057 & 207764.73 & NA & NA \\
\hline $\mathrm{SAF}^{32}$ & NA & 207380.5164 & 207813.37 & NA & NA \\
\hline $\mathrm{SA}^{32}$ & NA & 198352.6413 & 201595.19 & NA & NA \\
\hline $\mathrm{BBO}^{13}$ & 199102.59 & 198241.166 & 198413.45 & 115 & 41 \\
\hline $\mathrm{DE} / \mathrm{BBO}^{31}$ & 198828.57 & 198231.06 & 198326.66 & 132 & 43 \\
\hline
\end{tabular}




\subsubsection{System VI}

In this system, a 160 generators having multiple fuel options is considered. The load demand for this case is 43200 MW. The transmission loss is not considered here. The input data for this system is taken from a paper written by A.K. Barisal and R.C. Prusty ${ }^{32}$. The results of
QOGWO and GWO techniques is shown in Table 13. Table 14 describes the minimum, mean and worst cost of fuel obtained by various methods like ORCCRO ${ }^{12}, \mathrm{BBO}^{13}$, $\mathrm{DE} / \mathrm{BBO}^{31}$, ED-DE ${ }^{32}$, IGA-MU ${ }^{32}$, CGA-MU ${ }^{32} \mathrm{OIWO}^{32}$, GWO and QOGWO method. The fuel price convergence curve of this system is shown in Figure 8.

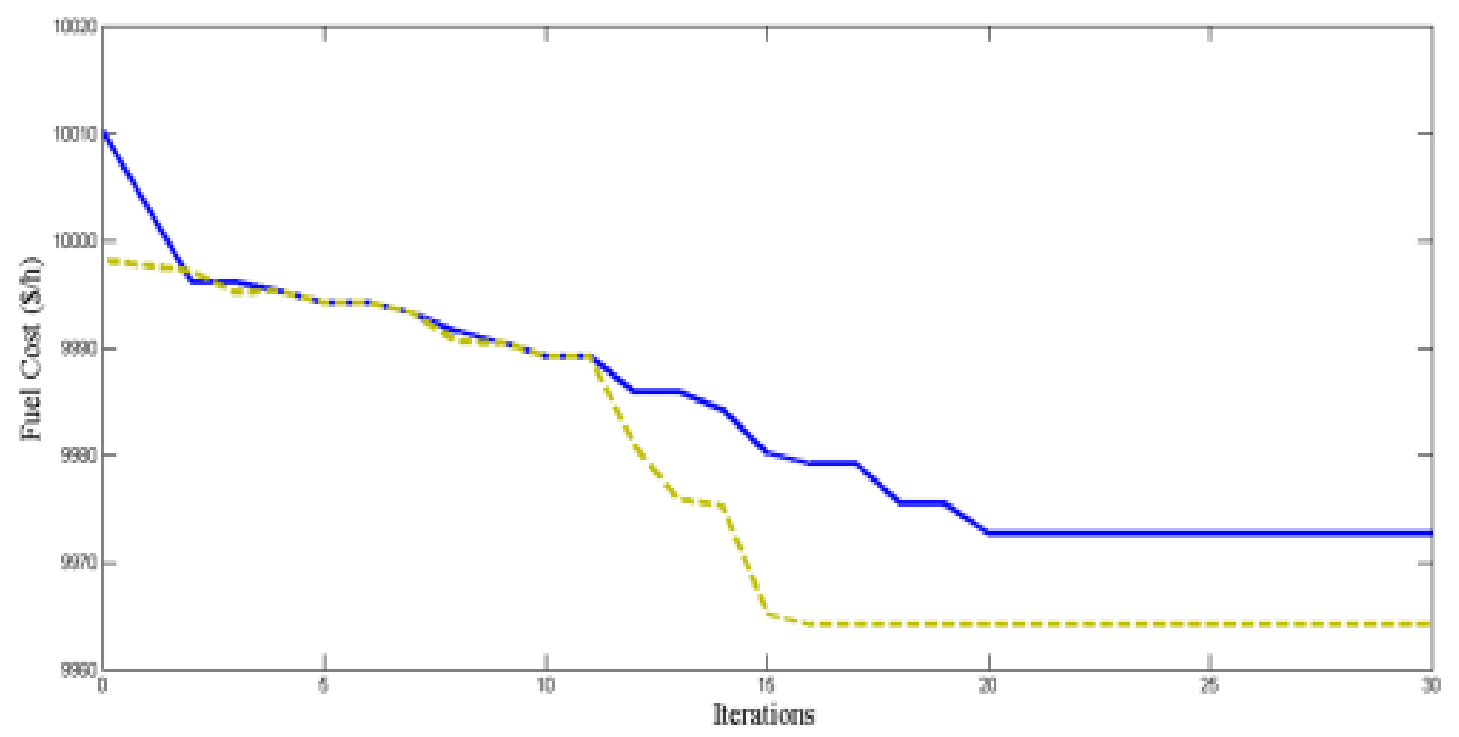

Figure 8. Convergence characteristics of system VI.

Table 13. Performance analysis of different methods for system VI taken after 50trails ( $P D=43200 \mathrm{MW})$

\begin{tabular}{|c|c|c|c|c|c|c|c|c|c|c|l|}
\hline \multicolumn{9}{|c|}{ GWO } & \multicolumn{7}{c|}{ QOGWO } \\
\hline $\begin{array}{c}\text { Un- } \\
\text { its }\end{array}$ & $\begin{array}{c}\text { Power } \\
\text { outputs } \\
(\mathbf{M W})\end{array}$ & $\begin{array}{c}\text { Un- } \\
\text { its }\end{array}$ & $\begin{array}{c}\text { Power } \\
\text { outputs } \\
(\mathbf{M W})\end{array}$ & $\begin{array}{c}\text { Un- } \\
\text { its }\end{array}$ & $\begin{array}{c}\text { Power } \\
\text { outputs } \\
(\mathbf{M W})\end{array}$ & $\begin{array}{c}\text { Un- } \\
\text { its }\end{array}$ & $\begin{array}{c}\text { Power } \\
\text { outputs } \\
(\mathbf{M W})\end{array}$ & $\begin{array}{c}\text { Un- } \\
\text { its }\end{array}$ & $\begin{array}{c}\text { Power } \\
\text { outputs } \\
(\text { MW })\end{array}$ & $\begin{array}{c}\text { Un- } \\
\text { its }\end{array}$ & $\begin{array}{c}\text { Power } \\
\text { outputs } \\
(M W)\end{array}$ \\
\hline 1 & 214.6001 & 55 & 266.9351 & 109 & 431.318 & 1 & 214.4864 & 55 & 269.2678 & 109 & 438.4047 \\
\hline 2 & 204.7634 & 56 & 240.0423 & 110 & 277.9399 & 2 & 212.4548 & 56 & 239.9063 & 110 & 275.7719 \\
\hline 3 & 281.6329 & 57 & 299.4076 & 111 & 222.1518 & 3 & 274.6084 & 57 & 292.4624 & 111 & 213.4571 \\
\hline 4 & 238.6973 & 58 & 241.38 & 112 & 207.5036 & 4 & 241.6550 & 58 & 239.7737 & 112 & 211.9588 \\
\hline 5 & 277.1996 & 59 & 437.0827 & 113 & 269.1646 & 5 & 273.0997 & 59 & 437.7344 & 113 & 269.6404 \\
\hline 6 & 241.3864 & 60 & 279.4758 & 114 & 244.8819 & 6 & 241.6521 & 60 & 279.0115 & 114 & 241.7905 \\
\hline
\end{tabular}


Table 13 Continued

\begin{tabular}{|c|c|c|c|c|c|c|c|c|c|c|c|}
\hline 7 & 285.67 & 61 & 219.912 & 115 & 267.4034 & 7 & 287.7118 & 61 & 214.4897 & 115 & 272.3082 \\
\hline 8 & 235.7428 & 62 & 208.014 & 116 & 242.597 & 8 & 243.9399 & 62 & 211.7117 & 116 & 238.6985 \\
\hline 9 & 425.9061 & 63 & 280.7645 & 117 & 289.9475 & 9 & 438.9299 & 63 & 271.5832 & 117 & 290.2308 \\
\hline 10 & 275.8244 & 64 & 238.1614 & 118 & 240.4427 & 10 & 275.8449 & 64 & 242.0581 & 118 & 238.0277 \\
\hline 11 & 221.6216 & 65 & 279.4439 & 119 & 437.2013 & 11 & 213.4646 & 65 & 269.2202 & 119 & 439.0474 \\
\hline 12 & 211.8362 & 66 & 237.2238 & 120 & 291.3842 & 12 & 211.2166 & 66 & 243.4007 & 120 & 275.8780 \\
\hline 13 & 279.7333 & 67 & 302.6804 & 121 & 217.5635 & 13 & 273.5998 & 67 & 292.4699 & 121 & 215.5350 \\
\hline 14 & 239.7701 & 68 & 241.3819 & 122 & 213.4731 & 14 & 240.9882 & 68 & 240.5802 & 122 & 210.4741 \\
\hline 15 & 264.3211 & 69 & 436.2868 & 123 & 275.9653 & 15 & 269.1794 & 69 & 435.1228 & 123 & 271.5557 \\
\hline 16 & 243.5408 & 70 & 275.1905 & 124 & 237.7568 & 16 & 242.5959 & 70 & 279.0103 & 124 & 240.4459 \\
\hline 17 & 297.1689 & 71 & 216.6148 & 125 & 276.8827 & 17 & 290.0992 & 71 & 214.4859 & 125 & 272.9668 \\
\hline 18 & 244.7464 & 72 & 213.1637 & 126 & 240.4433 & 18 & 241.7897 & 72 & 209.7313 & 126 & 240.7150 \\
\hline 19 & 439.1779 & 73 & 274.3264 & 127 & 297.2385 & 19 & 434.4025 & 73 & 273.6007 & 127 & 287.7276 \\
\hline 20 & 276.0322 & 74 & 243.5391 & 128 & 239.7791 & 20 & 276.9475 & 74 & 243.9399 & 128 & 242.5956 \\
\hline 21 & 210.6051 & 75 & 263.7286 & 129 & 427.7141 & 21 & 212.3993 & 75 & 271.8932 & 129 & 436.4365 \\
\hline 22 & 211.6995 & 76 & 238.2939 & 130 & 277.4549 & 22 & 210.9658 & 76 & 239.7719 & 130 & 275.8959 \\
\hline 23 & 269.6596 & 77 & 291.0201 & 131 & 216.1465 & 23 & 275.6108 & 77 & 290.0982 & 131 & 213.4583 \\
\hline 24 & 236.8124 & 78 & 240.5769 & 132 & 212.2094 & 24 & 240.4456 & 78 & 241.6563 & 132 & 211.7168 \\
\hline 25 & 266.2328 & 79 & 431.7919 & 133 & 278.5976 & 25 & 272.6824 & 79 & 436.4151 & 133 & 275.6235 \\
\hline 26 & 243.4069 & 80 & 276.3289 & 134 & 240.0441 & 26 & 240.5792 & 80 & 275.8721 & 134 & 239.6419 \\
\hline 27 & 285.7496 & 81 & 217.5026 & 135 & 259.9762 & 27 & 290.0976 & 81 & 214.4867 & 135 & 269.1072 \\
\hline 28 & 240.1768 & 82 & 208.2832 & 136 & 239.9135 & 28 & 243.6706 & 82 & 212.4560 & 136 & 240.8468 \\
\hline 29 & 432.3363 & 83 & 267.5013 & 137 & 292.1943 & 29 & 438.3719 & 83 & 273.6853 & 137 & 292.5700 \\
\hline 30 & 279.5421 & 84 & 238.025 & 138 & 240.1774 & 30 & 278.5974 & 84 & 241.1171 & 138 & 240.7143 \\
\hline
\end{tabular}


Table 13 Continued

\begin{tabular}{|c|c|c|c|c|c|c|c|c|c|c|c|}
\hline 31 & 223.7816 & 85 & 283.6076 & 139 & 439.9826 & 31 & 214.5197 & 85 & 269.1899 & 139 & 438.2133 \\
\hline 32 & 214.9326 & 86 & 243.1441 & 140 & 273.4101 & 32 & 210.7252 & 86 & 243.9393 & 140 & 279.0129 \\
\hline 33 & 278.5622 & 87 & 294.4825 & 141 & 215.6783 & 33 & 272.5917 & 87 & 290.2046 & 141 & 215.5135 \\
\hline 34 & 246.6263 & 88 & 236.4117 & 142 & 209.4936 & 34 & 243.6708 & 88 & 243.1330 & 142 & 213.9497 \\
\hline 35 & 281.8277 & 89 & 429.1283 & 143 & 276.2568 & 35 & 272.7212 & 89 & 437.9994 & 143 & 274.6892 \\
\hline 36 & 238.8329 & 90 & 272.8078 & 144 & 240.8676 & 36 & 241.2527 & 90 & 275.8643 & 144 & 242.1923 \\
\hline 37 & 294.6553 & 91 & 216.7571 & 145 & 266.8746 & 37 & 292.4739 & 91 & 214.4835 & 145 & 268.2304 \\
\hline 38 & 240.0565 & 92 & 210.7954 & 146 & 238.0274 & 38 & 240.3105 & 92 & 210.4739 & 146 & 242.3242 \\
\hline 39 & 426.5568 & 93 & 271.799 & 147 & 309.7367 & 39 & 436.6100 & 93 & 273.6028 & 147 & 294.8403 \\
\hline 40 & 291.0992 & 94 & 239.9063 & 148 & 244.35 & 40 & 275.8497 & 94 & 241.7901 & 148 & 239.9077 \\
\hline 41 & 216.745 & 95 & 266.9612 & 149 & 440 & 41 & 214.4845 & 95 & 269.1574 & 149 & 436.5000 \\
\hline 42 & 215.6718 & 96 & 244.4684 & 150 & 286.7391 & 42 & 210.4742 & 96 & 240.5801 & 150 & 276.0904 \\
\hline 43 & 272.0938 & 97 & 293.2304 & 151 & 215.3467 & 43 & 276.6243 & 97 & 292.4656 & 151 & 214.4825 \\
\hline 44 & 240.5761 & 98 & 240.9827 & 152 & 208.9302 & 44 & 241.2520 & 98 & 239.1001 & 152 & 210.9607 \\
\hline 45 & 262.0954 & 99 & 435.1629 & 153 & 271.0514 & 45 & 269.9264 & 99 & 438.7046 & 153 & 273.6007 \\
\hline 46 & 244.8809 & 100 & 273.3646 & 154 & 240.4477 & 46 & 241.2519 & 100 & 275.9626 & 154 & 240.8488 \\
\hline 47 & 295.8804 & 101 & 210.9514 & 155 & 268.4716 & 47 & 292.4482 & 101 & 213.4646 & 155 & 271.6976 \\
\hline 48 & 241.5271 & 102 & 211.7008 & 156 & 237.8934 & 48 & 242.3284 & 102 & 213.9396 & 156 & 242.3269 \\
\hline 49 & 420.8979 & 103 & 279.7549 & 157 & 290.7041 & 49 & 435.4686 & 103 & 272.5997 & 157 & 292.4563 \\
\hline 50 & 273.8595 & 104 & 236.4155 & 158 & 241.3857 & 50 & 278.8265 & 104 & 242.7299 & 158 & 241.2518 \\
\hline 51 & 210.9682 & 105 & 271.3423 & 159 & 429.7962 & 51 & 215.5313 & 105 & 272.7407 & 159 & 438.8034 \\
\hline 52 & 204.5304 & 106 & 238.1555 & 160 & 273.0223 & 52 & 212.4543 & 106 & 240.4454 & 160 & 275.8399 \\
\hline 53 & 281.448 & 107 & 292.5963 & \multirow{2}{*}{\multicolumn{2}{|c|}{$\begin{array}{c}\operatorname{Cost}(\$ / h)= \\
9972.5844\end{array}$}} & 53 & 273.5997 & 107 & 290.0987 & \multirow{2}{*}{\multicolumn{2}{|c|}{$\begin{array}{c}\text { Cost }(\$ / h)= \\
9964.1677\end{array}$}} \\
\hline 54 & 246.3391 & 108 & 238.0247 & & & 54 & 242.8654 & 108 & 242.9967 & & \\
\hline
\end{tabular}


Table 14. Performance analysis of different methods for system VI taken after 50trails (Load demand=43200MW)

\begin{tabular}{|c|c|c|c|c|c|}
\hline \multirow{2}{*}{ Methods } & \multicolumn{3}{|c|}{ Generation $\operatorname{cost}(\$ / h)$} & \multirow{2}{*}{ Time/iteration, s } & \multirow{2}{*}{$\begin{array}{l}\text { No of hits to } \\
\text { minimum } \\
\text { Solution }\end{array}$} \\
\hline & $\operatorname{Max} . \operatorname{cost}(\$ / h)$ & $\operatorname{Min} . \operatorname{cost}(\$ / h)$ & Average $(\$ / h)$ & & \\
\hline QOGWO & 9964.1961 & 9964.1697 & 9965.4929 & 0.18 & 49 \\
\hline GWO & 9974.9912 & 9972.5844 & 9972.6806 & 0.2 & 48 \\
\hline $\mathrm{DE} / \mathrm{BBO}^{31}$ & 10010.26 & 10007.05 & 10007.56 & 0.56 & 42 \\
\hline $\mathrm{BBO}^{13}$ & 10010.59 & 10008.71 & 10009.16 & 0.62 & 40 \\
\hline CGA-MU ${ }^{32}$ & NA & 10143.73 & NA & NA & NA \\
\hline ED-DE ${ }^{32}$ & NA & 10012.68 & NA & NA & NA \\
\hline ORCCRO $^{32}$ & 1004.45 & 10004.20 & 10004.21 & 0.019 & 48 \\
\hline IGA-MU ${ }^{32}$ & NA & 10042.47 & NA & NA & NA \\
\hline $\mathrm{OIWO}^{32}$ & 9983.998 & 9981.9834 & 9982.991 & 0.028 & 46 \\
\hline
\end{tabular}

\subsection{Parameter Tunning}

To check the impact of jumping rate on QOGWO algorithm, six systems have been taken and the program is executed for 50 individual trails for each system. The value of jumping rate has been varied from from 0.1-0.9. The results obtained by QOGWO algorithm is shown in

Table 15. Impact of jumping rate on QOGWO after 50 trials

\begin{tabular}{|c|c|c|c|c|c|c|c|}
\hline \multirow{2}{*}{$\begin{array}{c}\text { Jumping } \\
\text { rate }\end{array}$} & \multicolumn{2}{|c|}{ System I } & & & & \\
\cline { 2 - 8 } & $\begin{array}{c}\text { Load demand } \\
\mathbf{8 5 0 M W}\end{array}$ & $\begin{array}{c}\text { Load demand } \\
\mathbf{1 0 5 0 M W}\end{array}$ & System II & System III & System IV & System V & System VI \\
\cline { 2 - 8 } 0.1 & 8256.5479 & 10128.3312 & 2033.7912 & 15448.1236 & 9411940.1239 & 197942.9963 & 9971.2547 \\
\hline 0.2 & 8254.2403 & 10126.8796 & 2031.8569 & 15444.6548 & 9411936.9987 & 1979345.9613 & 9975.3398 \\
\hline 0.3 & 8254.8879 & 10126.8837 & 2035.9987 & 15444.1435 & 9411940.7453 & 197939.1236 & 9968.6540 \\
\hline $\mathbf{0 . 4}$ & $\mathbf{8 2 5 3 . 0 6 2 9}$ & $\mathbf{1 0 1 2 3 . 6 9 3 1}$ & $\mathbf{2 0 2 9 . 6 6 5 3}$ & $\mathbf{1 5 4 4 3 . 0 7 3 8}$ & $\mathbf{9 4 1 1 9 3 5 . 7 2 4 4}$ & $\mathbf{1 9 7 9 3 8 . 2 2 9 4}$ & $\mathbf{9 9 6 4 . 1 6 9 7}$ \\
\hline 0.5 & 8253.9873 & 10125.4789 & 2031.4712 & 15447.3689 & 9411937.6023 & 197945.0213 & 9966.2739 \\
\hline
\end{tabular}


Table 15 Continued

\begin{tabular}{|c|c|c|c|c|c|c|c|}
\hline 0.6 & 8254.0214 & 10125.9856 & 2032.4596 & 15448.9951 & 9411939.0213 & 197941.3982 & 9969.8802 \\
\hline 0.7 & 8254.2654 & 10127.5503 & 2032.8845 & 15444.5231 & 9411936.9541 & 197942.0147 & 9971.5014 \\
\hline 0.8 & 8254.4506 & 10126.4478 & 2034.1236 & 15445.3698 & 9411936.2204 & 197944.0596 & 9965.9871 \\
\hline 0.9 & 8255.6523 & 10125.1235 & 2032.1478 & 15446.3366 & 9411937.3943 & 197942.3987 & 9968.1182 \\
\hline
\end{tabular}

Table 15. From this table, it is found that when the value of jumping rate is 0.4 then cost obtained by QOGWO algorithm is minimum for all systems. No changes are found when the value of jumping rate is above or below 0.4.

\subsection{Comparative Analysis}

\subsubsection{Robustness and Solution Quality}

The best results obtained by QOGWO algorithm are presented in Tables 1, 3, 5,7,9,11 and 13. It is found that QOGWO method gives better results as compared to other well-known optimization techniques. The best, average and worst values for different optimization techniques are presented in Tables 2, 4, 6, 8, 10, 12 and 14 . The performance of QOGWO algorithm is judged after running the program for 50 numbers of trials. Out of 50 trails, QOGWO hits the minimum solution 48 times for system I, 47 times for system II, 50 times for system III, 50 times for system IV, 50 times for system V and 49 times for system VI. Therefore, it is found that the success rate of QOGWO is $92 \%, 90 \%, 96 \%, 100 \%, 100 \%$, $100 \%$ and $98 \%$ respectively. Therefore, from these simulation results, it is seen that QOGWO algorithm shows better performance in terms of robustness and as well as solution quality when compared with GWO and other previously developed optimization techniques.

\subsubsection{Computational Efficiency}

The QOGWO algorithm takes less time to reach minimum solution as compared to other meta-heuristic optimization techniques. From tables 2, 4, 6, 8, 10, 12 and 14 it is found that, the computational efficiency of QOGWO is better as compared to recently developed optimization techniques. It is also seen that when oppositional based learning is applied in GWO algorithm then the convergence rate becomes faster as compared to other techniques such as GWO, BBO, DE/BBO, RCCRO, EMA and so on.

\subsubsection{Statistical Analysis}

In recent years, various statistical methods $s^{39,40}$ has been used for finding out robustness of different algorithms. In this paper, Friedman test and Quade test are chosen to assess the solution quality of QOGWO algorithm as compared to GWO and other recently developed optimization techniques. Table 16 describes the statistical analysis of QOGWO, GWO, DE/BBO, BBO algorithms. Table 16 shows that $\mathrm{F}$-statistic (Chi-Square) value is 9 and Q-statistic value is 15. It is found that F-statistic value is greater than its corresponding critical chi-square value (7.82) and Q-statistic value is also greater than its critical value (4.76). It is also found that $\mathrm{p}$-values obtained by Friedman test and Quade test are less as compared to p-value at 5\% significance level. Therefore, there is major dissimilarity between the algorithms. Depending on the average errors evaluated for different cases, the algorithms are ranked and results are shown in Table 16. Therefore, it is clear that rank achieved by QOGWO algorithm is minimum. The average errors of different algorithms are shown in Table 17. Therefore, it may be concluded that in terms of quality solution the QOGWO algorithm gives 
Table 16. Positions achieved by Quade and Friedman tests for system II, III, IV. The F-statistic and p- value for Friedman test and Q-statistic value and p-value for Quade test are also shown

\begin{tabular}{|c|c|c|c|c|c|c|c|c|c|}
\hline \multicolumn{9}{|c|}{ Friedman Test } & \multicolumn{5}{c|}{ Quade Test } \\
\hline Systems & QOGWO & GWO & DE/BBO & BBO & Systems & QOGWO & GWO & DE/BBO & BBO \\
\hline system II & 1 & 2 & 3 & 4 & system II & -4.5 & -1.5 & 1.5 & 4.5 \\
\hline system III & 1 & 2 & 3 & 4 & system III & -3 & -1 & 1 & 3 \\
\hline system IV & 1 & 2 & 3 & 4 & system IV & -1.5 & -0.5 & 0.5 & 1.5 \\
\hline \multicolumn{3}{|c|}{ Statistic 9 } \\
\multicolumn{3}{|c|}{ p-value 0.0293} & & & & Statistic 12 & & p-value 0.0060 \\
\hline
\end{tabular}

Table 17. Average errors obtained in system II, system III and system IV

\begin{tabular}{|c|c|c|c|c|}
\hline Systems & QOGWO & GWO & DE/BBO & BBO \\
\hline system II & 0 & 5.1447023 & 5301.56657 & 5702.433833 \\
\hline system III & 0 & 0.5435 & 388.4306 & 475.2206 \\
\hline system IV & 1.3232 & 8.5109 & 43.3903 & 44.9903 \\
\hline
\end{tabular}

better result in a robust manner as compared to other recently developed optimization techniques.

\section{Conclusion}

In this paper, Quasi Oppositional Grey Wolf Optimizer technique has been implemented successfully for solving various ELD issues. Six different systems having 3, 5, 6, 38, 110 and 160 units have been used here. The simulation results of QOGWO technique have been compared to other optimization technique such as GWO, BBO, DE/BBO, ORCCRO, TLBO, EMA and so on. Simulation results reveal the supremacy of this algorithm in terms of consistency, solution quality and computational efficiency. The robustness of this algorithm is also judged by some statistical analysis like Friedman and Quade test. From these statistical analysis it is clear that in terms of robustness QOGWO also gives better result as compared to other soft computing methods. Therefore, it may be concluded that QOGWO is a strong optimization tool for solving various complex ELD and other non-convex optimization problems.

\section{References}

1. Fanshel S, Lynes ES. Economic power generation using linear programming. IEEE Transaction on Power Apparatus System. 1964; 83(4):347-56. https://doi.org/10.1109/ TPAS.1964.4766011.

2. Wood J, Wollenberg BF. Power generation operation and control. 2nd edition John Wiley and Sons; 2013. p. $1-9$.

3. Bard JF. Short-term scheduling of thermal-electric generators using Lagrangian relaxation. Operation Research. 1988; 36(5):756-66. https://doi.org/10.1287/opre.36.5.756. 
4. Walters DC, Sheble GB. Genetic algorithm solution of economic dispatch with valve point loadings. IEEE Transactions on Power System. 1993; 8(3):1325-31. https:// doi.org/10.1109/59.260861.

5. Panigrahi CK, Chattopadhyay PK, Chakrabarti RN, Basu M. Simulated annealing technique for dynamic economic dispatch. Electronic Power Components System. 2006; 34(5):577-86.https://doi.org/10.1080/15325000500360843.

6. Dieu VN, Peter S, Ongsakul W. Cuckoo search algorithm for non-convex economic dispatch. IET Generation, Transmission and Distribution. 2013; 7(6):645-54. https:// doi.org/10.1049/iet-gtd.2012.0142.

7. Gaing ZL. Particle swarm optimization to solving the economic dispatch considering the generator constraints. IEEE Transaction on Power System. 2003; 18(3):1187-95. https:// doi.org/10.1109/TPWRS.2003.814889.

8. Dinu CS. A new modified artificial bee colony algorithm for the economic dispatch problem. Energy Conversion and Management. 2015; 89:43-62. https://doi.org/10.1016/j. enconman.2014.09.034.

9. Nomana N, Iba H. Differential evolution for economic load dispatch problems. Electronics Power System and Research. 2008; 78(3):1322-33. https://doi.org/10.1016/j. epsr.2007.11.007.

10. Cai J, Li Q, Li L, Peng H, Yang Y. A fuzzy adaptive chaotic ant swarm optimization for economic dispatch. International Journal of Electronic Power Energy System. 2012; 341):15460. https://doi.org/10.1016/j.ijepes.2011.09.020.

11. Bhattacharjee K, Bhattacharya A, Dey SH. Chemical reaction optimisation for different economic dispatch problems. IET General Transmission Distribution. 2014; 8(3):530-41. https://doi.org/10.1049/iet-gtd.2013.0122.

12. Bhattacharjee K, Bhattacharya A, Dey SH. Oppositional real coded chemical reaction optimization for different economic dispatch problems. International Journal of Electronic Power Energy System. 2014; 55:378-91. https:// doi.org/10.1016/j.ijepes.2013.09.033.

13. Bhattacharya A, Chattopadhyay PK. Biogeography-based optimization for different economic load dispatch problems. IEEE Transmission Power System. 2010; 25(2):1064-77. https://doi.org/10.1109/TPWRS.2009.2034525.

14. Banerjee S, Maity D, Chanda CK. Teaching learning based optimization for economic load dispatch problem considering valve point loading effect. Electronic Power \& Energy System. 2015; 73:456-64. https://doi.org/10.1016/j. ijepes.2015.05.036.

15. Ghorbani N, Babaei E. Exchange market algorithm for economic load dispatch. International Journal of Electronic Power Energy System. 2016; 75:19-27. https://doi. org/10.1016/j.ijepes.2015.08.013.
16. Nguyen TT, Vo DN. The application of one rank cuckoo search algorithm for solving economic load dispatch problems. Applied Soft Computer. 2015; 37:763-73. https://doi. org/10.1016/j.asoc.2015.09.010.

17. Kumar S, Naresh R. Nonconvex economic load dispatch using an efficient real coded genetic algorithm. Applied of Soft Computer. 2015; 37:321-9.

18. Mandal B, Roy PK, Mandal S. Economic load dispatch using krill herd algorithm. International Journal Electronic Power Energy System. 2014; 57:1-10. https://doi.org/10.1016/j. ijepes.2013.11.016.

19. Kamboj VK, Bath SK, Dhillon JS. Solution of non-convex economic load dispatch problem using Grey WolfOptimizer Neural Comput and Application. 2016; 27(5):1301-16. https://doi.org/10.1007/s00521-015-1934-8.

20. Kamboj VK, Bhadoria A, Bath SK. Solution of non-convex economic load dispatch problem for small scale power systems using ant lion optimizer. Neural Computer and Application; 2016. https://doi.org/10.1007/s00521-0151934-8.

21. Basu M. Kinetic gas molecule optimization for non-convex economic dispatch problem. International Journal of Electronic Power Energy System. 2016; 80:325-32. https:// doi.org/10.1016/j.ijepes.2016.02.005.

22. Sinha N, Chakrabarti R, Chattopadhyay PK. Evolutionary programming techniques for economic load dispatch. IEEE Transmission Evolutionary Computer. 2003; 7(1):83-94. https://doi.org/10.1109/TEVC.2002.806788.

23. Coelho LDS, Mariani VC. Combining of chaotic differential evolution and quadratic programming for economic dispatch optimization with valve-point effect. IEEE Transactions on Power System. 2006; 21(2):989-96. https:// doi.org/10.1109/TPWRS.2006.873410.

24. Adhinarayanan T, Sydulu MA. directional search genetic algorithm to the economic dispatch problem with prohibited operating zones. Proceedings of IEEE/PES Transmission and Distribution Conference Exposition; 2008. p. 1-5.

25. Selvakumar I, Thanushkodi K. A new particle swarm optimization solution to nonconvex economic dispatch problems. IEEE Transactions on Power System. 2007; 22(1):42-51. https://doi.org/10.1109/TPWRS.2006.889132.

26. Chiou JP. Variable scaling hybrid differential evolution for large-scale economic dispatch problems. Electronic Power System Research. 2007; 77(3-4):212-18. https://doi. org/10.1016/j.epsr.2006.02.013.

27. Panigrahi BK, Pandi VR. Bacterial foraging optimization Nelder-Mead hybrid algorithm for economic load dispatch. IET Generation Transmission Distribution. 2008; 2(4):556-65. https://doi.org/10.1049/iet-gtd:20070422. 
28. Chaturvedi KT, Pandit M, Srivastava L. Self-organizing hierarchical particle swarm optimization for nonconvex economic dispatch. IEEE Transmission Power System. 2008; 23(3):1079-87. https://doi.org/10.1109/ TPWRS.2008.926455.

29. Vlachogiannis JK, Lee KY. Economic load dispatch - A comparative study on heuristic optimization techniques with an improved coordinated aggregation-based PSO. IEEE Transmission Power System. 2009; 24(2):991-1001. https://doi.org/10.1109/TPWRS.2009.2016524.

30. Park JB, Jeong YW, Shin JR, Lee KY. An improved particle swarm optimization for nonconvex economic dispatch problems. IEEE Transmission Power System. 2010; 25(1):156-66. https://doi.org/10.1109/TPWRS.2009.2030293.

31. Bhattacharya A, Chattopadhyay PK. Hybrid differential evolution with biogeography-based optimization for solution of economic load dispatch. IEEE Transmission Power System. 2010; 25(4):1955-64. https://doi.org/10.1109/ TPWRS.2010.2043270.

32. Barisal AK, Prusty RC. Large scale economic dispatch of power systems using oppositional invasive weed optimization. Applied Soft Computer. 2015; 29:122-37. https://doi. org/10.1016/j.asoc.2014.12.014.

33. Roy PK, Bhui S, Paul C. Solution of economic load dispatch using hybrid chemical reaction optimization approach. Applied Soft Computer. 2014; 24:109-25. https://doi. org/10.1016/j.asoc.2014.07.013.

34. Amjady N, Sharifzadeh H. Solution of non-convex economic dispatch problem considering valve loading effect by a new
Modified Differential Evolution algorithm. International Journal of Electronic Power Energy System. 2010; 32:893903. https://doi.org/10.1016/j.ijepes.2010.01.023.

35. Sen T, Mathur HD. A new approach to solve Economic Dispatch problem using A Hybrid ACO-ABC-HS optimization algorithm. International Journal of Electronic Power Energy System. 2016; 78:735-44. https://doi.org/10.1016/j. ijepes.2015.11.121.

36. Mirjalili S, Mirjalili SM, Lewis A. Grey wolf opimizer. Advance Engineering Software. 2014; 69:46-61. https://doi. org/10.1016/j.advengsoft.2013.12.007.

37. Tizhoosh H. Opposition-based learning: A new scheme for machine intelligence. Proceedings of the International Conference on Computational Intelligence for Modelling Control and Automation; 2005. p. 695-701. https://doi. org/10.1109/CIMCA.2005.1631345.

38. Eegezer M, Simon D, Du D. Oppositional biogeographybased optimization. Proceedings of the IEEE International Conference on Systems Man and cybernetics San Antonio TX, USA; 2009. p. 1009-14.

39. Derac J, Garcia S, Molina D, Herrera F. A practical tutorial on the use of nonparametric statistical tests as a methodology for comparing evolutionary and swarm intelligence algorithms. Swarm Evolutionary Computer. 2011; 1:3-18. https://doi.org/10.1016/j.swevo.2011.02.002.

40. Shenkin DJ. Hand book of parametric and no parametric statistical procedures. 4th Edition. Chapman \& Hall/CRC; 2006. 